Supporting Information for:

\title{
Elucidation of Thorium Redox-Active Ligand Complexes: Evidence for a Thorium-Tri(radical) Species
}

D. M. Ramitha Y. P. Rupasinghe, ${ }^{\mathrm{a}}$ Himanshu Gupta, ${ }^{\mathrm{b}}$ Makayla R. Baxter, ${ }^{\mathrm{a}}$ Robert F. Higgins, ${ }^{\mathrm{b}}$ Matthias Zeller, ${ }^{\mathrm{a}}$ Eric J. Schelter, ${ }^{\mathrm{b}}$ and Suzanne C. Bart ${ }^{* a}$

${ }^{a}$ H. C. Brown Laboratory, Department of Chemistry, Purdue University, West Lafayette, Indiana 47907, USA

${ }^{\text {b}}$ P. Roy and Diana T. Vagelos Laboratories, Department of Chemistry, University of Pennsylvania, 231 South $34^{\text {th }}$ Street, Philadelphia, Pennsylvania 19104, USA. 


\section{Table of Contents}

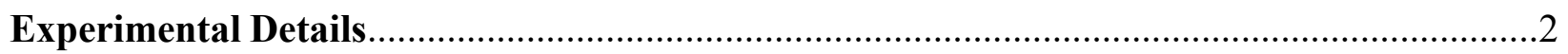

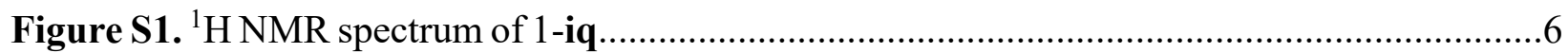

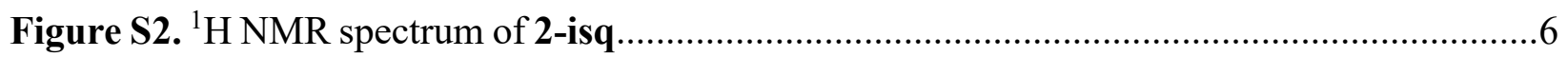

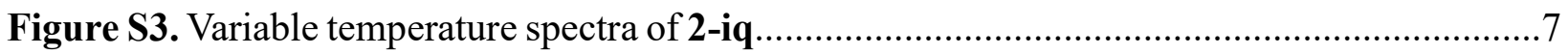

Figure S4. NMR tube reaction of addition of 1 equiv. of ${ }^{\mathrm{dipp}}$ iq to 1 -iq...................................... 7

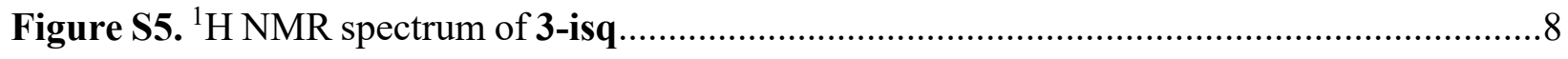

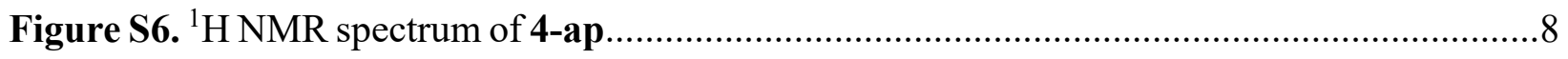

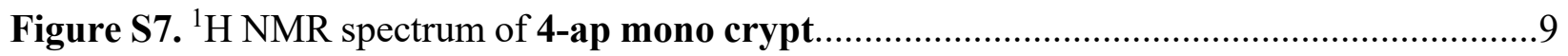

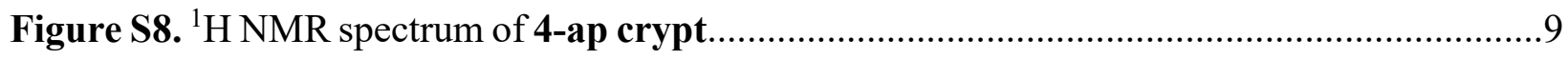

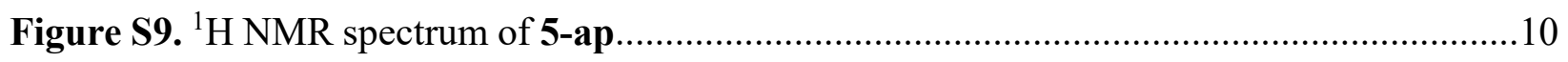

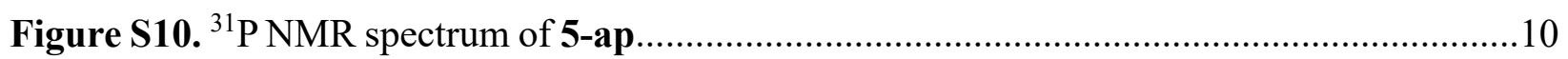

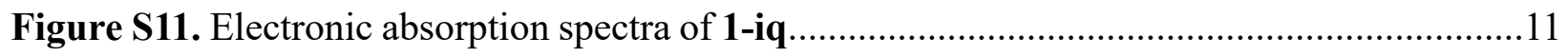

Figure S12. Electronic absorption spectra of 4-ap and 4-ap mono crypt...................................11

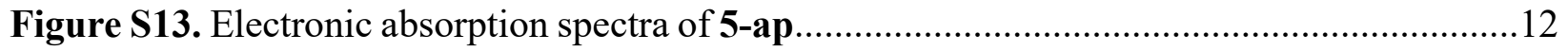

Figure S14. IR Spectra (KBr pellet) of 1-iq, 2-iq, and 3-isq..................................................12

Figure S15. IR Spectra (KBr pellet) of 4-ap, 4-ap mono crypt, and 4-ap crypt..........................13

Figure S16. IR Spectra (KBr pellet) of 5-ap.....................................................................13

Figure S17. Molecular structure of 4-ap mono crypt.............................................................14

Figure S18. Molecular structures of 1-iq, 2-iq, 3-isq, 4-ap, 4-ap crypt, and 5-ap.......................15

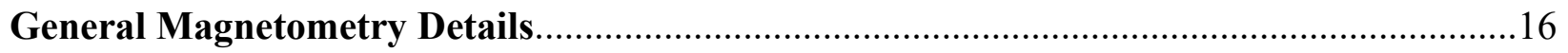

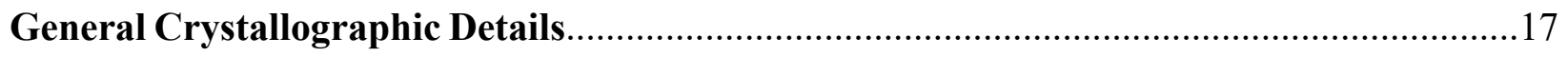

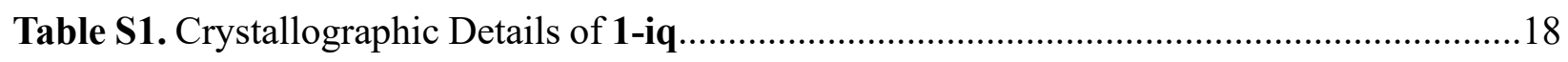

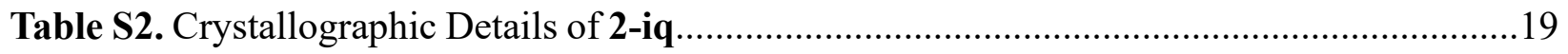

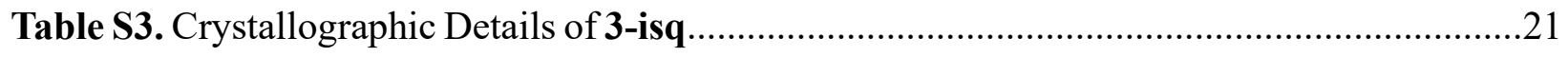

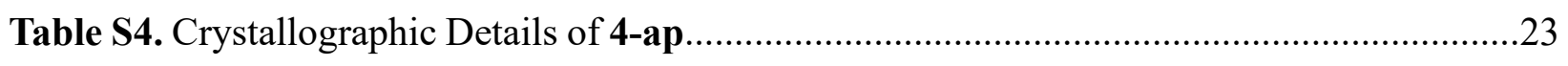

Table S5. Crystallographic Details of 4-ap mono crypt ……………...........................................25

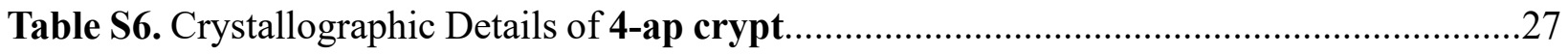

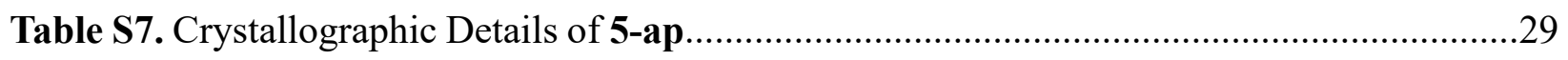




\section{Experimental Details}

General Considerations. All air- and moisture-sensitive manipulations were performed using standard Schlenk techniques or in an MBraun inert atmosphere drybox with an atmosphere of purified nitrogen. The MBraun drybox was equipped with a cold well designed for freezing samples in liquid nitrogen as well as two $-35^{\circ} \mathrm{C}$ freezers for cooling samples and crystallizations. Solvents for sensitive manipulations were dried and deoxygenated using literature procedures with a Seca solvent purification system. ${ }^{1}$ Benzene-d6 was purchased from Cambridge Isotope Laboratories, dried with molecular sieves and sodium, and degassed by three freeze-pump-thaw cycles. Pyridine-d5 was purchased from Cambridge Isotope Laboratories, dried over $\mathrm{CaH}_{2}$, distilled, degassed by three freeze-pump-thaw cycles, and stored over molecular sieves 24 hours before use. 4,6-Di-tert-butyl-2-[(2,6-diisopropylphenyl)imino]quinone ( ${ }^{\text {dipp }}$ iq), ${ }^{2}$ potassium graphite $\left(\mathrm{KC}_{8}\right),{ }^{3}$ and thorium tetrachloride $\left(\mathrm{ThCl}_{4}(\mathrm{dme})_{2}\right)^{4}$ were prepared according to literature procedures. [2.2.2] Cryptand (crypt) and triphenylphosphine oxide $\left(\mathrm{OPPh}_{3}\right)$ were purchased from Fischer Scientific and Sigma Aldrich respectively and dried under vacuum on a Schlenk line overnight prior to use.

${ }^{1} \mathrm{H}$ NMR spectra were recorded on a Varian Inova 300 or Bruker AV-III-HD-400 spectrometer operating at 299.99 and $400.13 \mathrm{MHz}$, respectively. Variable temperature ${ }^{1} \mathrm{H}$ NMR spectra were recorded on a Bruker AV-III-HD-500 spectrometer operating at $500.13 \mathrm{MHz}$. All chemical shifts were reported relative to the peak for $\mathrm{SiMe}_{4}$ using ${ }^{1} \mathrm{H}$ (residual) chemical shifts of the solvent as a secondary standard. The spectra for paramagnetic molecules were obtained using an acquisition time of $0.5 \mathrm{~s}$; thus, the peak widths reported have an error of $\pm 2 \mathrm{~Hz}$. For paramagnetic molecules, the ${ }^{1} \mathrm{H}$ NMR data are reported with the chemical shift, followed by the peak width at half height in hertz, the integration value, and where possible, the peak assignment. ${ }^{31} \mathrm{P}$ NMR spectra were recorded on a Bruker AV-III-400-HD spectrometer operating at 161.98 $\mathrm{MHz}$. Variable temperature ${ }^{1} \mathrm{H}$ spectra were recorded on a Bruker AV-III-HD-500 spectrometer operating at 500.13 MHz. Electronic absorption measurements were recorded at $294 \mathrm{~K}$ in THF in sealed, $1 \mathrm{~cm}$ quartz cuvettes with a Cary 6000i UV-vis/NIR spectrophotometer. Elemental analyses were performed by Midwest Microlab, LLC, in Indianapolis, IN. Solid state infrared spectra were recorded using a Thermo Nicolet 6700 spectrophotometer. Samples were made by crushing the solids, mixing with dry $\mathrm{KBr}$, and pressing into a pellet.

Synthesis of $\mathbf{T h}\left({ }^{(i p p i q)} \mathbf{C l}_{4}(\mathbf{d m e})_{2}\right.$ (1-iq). A $20 \mathrm{~mL}$ scintillation vial was charged with $\mathrm{ThCl}_{4}(\mathrm{dme})_{2}(0.100 \mathrm{~g}, 0.180 \mathrm{mmol})$ and $3 \mathrm{~mL}$ pentane. A separate $20 \mathrm{~mL}$ scintillation vial was charged with ${ }^{\text {dipp }}$ iq $(0.069 \mathrm{~g}, 0.180 \mathrm{mmol})$, dissolved in $3 \mathrm{~mL}$ pentane, and added dropwise to the stirring $\mathrm{ThCl}_{4}(\mathrm{dme})_{2}$ slurry. Precipitation of a light brown solid was observed. After stirring for 3 days, the precipitate was filtered through a fine porosity frit and the resulting light brown solid was washed with pentane $(10 \mathrm{~mL})$. Volatiles were removed in vacuo to afford a light brown powder $(0.180 \mathrm{~g}, 0.213 \mathrm{mmol}, 79 \%$ yield$)$, assigned as $\mathrm{Th}\left({ }^{\mathrm{dipp}} \mathrm{iq}\right) \mathrm{Cl}_{4}(\mathrm{dme})_{2}$ (1-iq). Red-orange, block-shaped crystals suitable for X-ray analysis were grown from a THF solution layered with ether (1:2 ratio) overnight at $-35^{\circ} \mathrm{C}$. Elemental analysis of $\mathrm{C}_{30} \mathrm{H}_{49} \mathrm{NO}_{5} \mathrm{Cl}_{4} \mathrm{Th}$ : calculated, $\mathrm{C}, 43.74$; 
$\mathrm{H}, 6.15 ; \mathrm{N}, 1.50$. Found, $\mathrm{C}, 39.56 ; \mathrm{H}, 5.67 ; \mathrm{N}, 0.82$. This compound had incomplete combustion for elemental analysis over several measurements; we attribute this to the compound decomposing during the measurements. ${ }^{1} \mathrm{H} \mathrm{NMR}\left(\mathrm{C}_{6} \mathrm{D}_{6}, 300 \mathrm{MHz}, 25^{\circ} \mathrm{C}\right): \delta=0.70\left(\mathrm{~s}, 9 \mathrm{H}, \mathrm{C}\left(\mathrm{CH}_{3}\right)_{3}\right), 1.10(\mathrm{~d}$, $\left.6 \mathrm{H}, \mathrm{CH}\left(\mathrm{CH}_{3}\right)_{2}\right), 1.38$ (s, 9H, $\left.\mathrm{C}\left(\mathrm{CH}_{3}\right)_{3}\right), 1.65$ (d, 6H, $\left.\mathrm{CH}\left(\mathrm{CH}_{3}\right)_{2}\right), 3.27$ (s, 4H, dme), 3.34 (s, 4H, dme), 3.77 (s, 6H, dme), 3,78 (s, 6H, dme), 3.84 (sept, 2H, $\left.\mathrm{CH}\left(\mathrm{CH}_{3}\right)_{2}\right), 6.20$ (d, 1H, CH), 7.10 (s, $1 \mathrm{H}, \mathrm{CH}), 7.13(\mathrm{~d}, 1 \mathrm{H}, \mathrm{CH}), 7.20(\mathrm{~s}, 1 \mathrm{H}, \mathrm{CH}), 7.22(\mathrm{~d}, 1 \mathrm{H}, \mathrm{CH})$.

Synthesis of $\mathbf{T h}\left({ }^{\text {dippiq }}\right)_{2} \mathbf{C l}_{4}$ (2-iq). A $20 \mathrm{~mL}$ scintillation vial was charged with $\mathrm{ThCl}_{4}(\mathrm{dme})_{2}(0.100 \mathrm{~g}, 0.180 \mathrm{mmol})$ and $3 \mathrm{~mL}$ diethyl ether. A separate $20 \mathrm{~mL}$ scintillation vial was charged with dippiq $(0.343 \mathrm{~g}, 0.902 \mathrm{mmol})$, dissolved in $3 \mathrm{~mL}$ diethyl ether, and added dropwise to the stirring $\mathrm{ThCl}_{4}(\mathrm{dme})_{2}$ slurry. A dark brown slurry was observed. After stirring overnight, the precipitate was filtered through a fine porosity frit and the resulting dark brown solid was washed with pentane $(25 \mathrm{~mL})$. Volatiles were removed in vacuo to afford a dark brown powder $(0.144 \mathrm{~g}$, $0.127 \mathrm{mmol}, 71 \%$ yield), assigned as $\mathrm{Th}\left({ }^{\mathrm{dipp}}{ }_{\mathrm{iq}}\right)_{2} \mathrm{Cl}_{4}$ (2-iq). Red-orange, needle-shaped crystals suitable for X-ray analysis were grown by slow diffusion of pentane into a DCM solution (1:1 ratio) overnight at $-35^{\circ} \mathrm{C}$. Elemental analysis of $\mathrm{C}_{52} \mathrm{H}_{74} \mathrm{~N}_{2} \mathrm{O}_{2} \mathrm{Cl}_{4}$ Th: calculated, C, 55.12; $\mathrm{H}, 6.58$; $\mathrm{N}, 2.47$. Found, $\mathrm{C}, 54.60 ; \mathrm{H}, 6.43 ; \mathrm{N}, 2.28 .{ }^{1} \mathrm{H}$ NMR $\left(\mathrm{C}_{6} \mathrm{D}_{6}, 300 \mathrm{MHz}, 25^{\circ} \mathrm{C}\right): \delta=0.64(\mathrm{~s}, 18 \mathrm{H}$, $\left.\mathrm{C}\left(\mathrm{CH}_{3}\right)_{3}\right), 1.02\left(\mathrm{~d}, 12 \mathrm{H}, \mathrm{CH}\left(\mathrm{CH}_{3}\right)_{2}\right), 1.37\left(\mathrm{~s}, 18 \mathrm{H}, \mathrm{C}\left(\mathrm{CH}_{3}\right)_{3}\right), 1.63$ (br d, $\left.12 \mathrm{H}, \mathrm{CH}\left(\mathrm{CH}_{3}\right)_{2}\right), 3.89$ (br $\left.\mathrm{m}, 4 \mathrm{H}, \mathrm{CH}\left(\mathrm{CH}_{3}\right)_{2}\right), 6.17(\mathrm{~d}, 2 \mathrm{H}, \mathrm{CH}), 7.10(\mathrm{~d}, 2 \mathrm{H}, \mathrm{CH}), 7.13(\mathrm{~d}, 2 \mathrm{H}, \mathrm{CH}), 7.20(\mathrm{~s}, 2 \mathrm{H}, \mathrm{CH}), 7.22$ $(\mathrm{d}, 2 \mathrm{H}, \mathrm{CH})$.

Synthesis of $\mathbf{T h}$ (dippisq) ${ }_{3} \mathbf{C l}$ (3-isq). A $20 \mathrm{~mL}$ scintillation vial was charged with $\mathrm{ThCl}_{4}(\mathrm{dme})_{2}(0.250 \mathrm{~g}, 0.451 \mathrm{mmol})$ and $3 \mathrm{~mL}$ THF. A separate $20 \mathrm{~mL}$ scintillation vial was charged with ${ }^{\text {dippiq }}(0.514 \mathrm{~g}, 1.354 \mathrm{mmol})$, dissolved in $3 \mathrm{~mL}$ THF, and added dropwise to the stirring $\mathrm{ThCl}_{4}(\mathrm{dme})_{2}$ slurry. Potassium graphite $(0.171 \mathrm{~g}, 1.26 \mathrm{mmol})$ was added slowly $(\sim 30 \mathrm{mg}$ every 45 seconds), resulting in a rapid color change from red-brown to dark green. After 2 hours, the solution was filtered over a celite pad and volatiles were removed in vacuo. The crude mixture was recrystallized from cyclopentane to afford a dark green powder $(0.363 \mathrm{~g}, 0.258 \mathrm{mmol}, 57 \%)$, assigned as $\mathrm{Th}\left({ }^{\mathrm{dipp}}\right.$ isq $_{3} \mathrm{Cl}$ (3-isq). Dark green, rod-shaped crystals suitable for $\mathrm{X}$-ray analysis were grown from a concentrated THF solution at $-35{ }^{\circ} \mathrm{C}$. Elemental analysis of $\mathrm{C}_{78} \mathrm{H}_{111} \mathrm{~N}_{3} \mathrm{O}_{3} \mathrm{ClTh}$ : calculated, C, 66.62; H, 7.96; N, 2.99. Found, $\mathrm{C}, 66.72 ; \mathrm{H}, 8.22 ; \mathrm{N}, 3.00 .{ }^{1} \mathrm{H}$ NMR $\left(\mathrm{C}_{6} \mathrm{D}_{6}, 300\right.$ $\mathrm{MHz}, 25{ }^{\circ} \mathrm{C}$ ): $\delta=1.84\left(\mathrm{~d}, 6 \mathrm{H}, \mathrm{CH}\left(\mathrm{CH}_{3}\right)_{2}\right), 1.98\left(\mathrm{~s}, 27 \mathrm{H}, \mathrm{C}\left(\mathrm{CH}_{3}\right)_{3}\right), 6.80$ (br s, $\left.9 \mathrm{H}, \mathrm{CH}\left(\mathrm{CH}_{3}\right)_{2}\right)$, 9.99 (br s, 9H, $\left.\mathrm{CH}\left(\mathrm{CH}_{3}\right)_{2}\right), 10.61$ (br s, 9H, $\left.\mathrm{CH}\left(\mathrm{CH}_{3}\right)_{2}\right), 10.98$ (br s, $\left.9 \mathrm{H}, \mathrm{CH}\left(\mathrm{CH}_{3}\right)_{2}\right), 13.64$ (s, 27H, $\left.\mathrm{C}\left(\mathrm{CH}_{3}\right)_{3}\right), 14.89$ (s, 1H, CH), 18.87 (s, 1H, CH), 20.44 (s, 1H, CH), 48.35 (s, 1H, CH), 48.45 (s, $1 \mathrm{H}, \mathrm{CH})$.

Synthesis of $\mathbf{T h}$ (dipp $\left.{ }^{\text {ap) }}\right)_{3} \mathbf{K}_{2}$ (THF) $)_{2}$ (4-ap). A $20 \mathrm{~mL}$ scintillation vial was charged with $\mathrm{ThCl}_{4}(\mathrm{dme})_{2}(0.300 \mathrm{~g}, 0.541 \mathrm{mmol})$ and $3 \mathrm{~mL}$ THF. A separate $20 \mathrm{~mL}$ scintillation vial was charged with ${ }^{\text {dippiq }}(0.617 \mathrm{~g}, 1.624 \mathrm{mmol})$, dissolved in $3 \mathrm{~mL}$ THF, and added dropwise to the stirring $\mathrm{ThCl}_{4}(\mathrm{dme})_{2}$ slurry. Potassium graphite $(0.476 \mathrm{~g}, 3.519 \mathrm{mmol})$ was added slowly $(\sim 30 \mathrm{mg}$ every 45 seconds), resulting in rapid color changes from red-brown to dark green to yellow. After stirring overnight, the solution was filtered through a celite pad and volatiles were removed in vacuo. The crude mixture was dissolved in pentane and a few drops of THF and recrystallized 
overnight. The resulting yellow crystalline powder was washed with cold pentane $(3 \times 5 \mathrm{~mL})$ and volatiles were removed in vacuo to afford a yellow powder $(0.742 \mathrm{~g}, 0.466 \mathrm{mmol}, 86 \%$ yield $)$, assigned as $\mathrm{Th}\left({ }^{\mathrm{dipp}} \mathrm{ap}\right)_{3} \mathrm{~K}_{2}(\mathrm{THF})_{2}$ (4-ap). Yellow, plate-shaped crystals suitable for X-ray analysis were from a concentrated toluene solution at $-35{ }^{\circ} \mathrm{C}$. Elemental analysis of $\mathrm{C}_{78} \mathrm{H}_{111} \mathrm{~N}_{3} \mathrm{O}_{3} \mathrm{~K}_{2}$ Th.(THF)(Tol): calculated, C, 66.26; H, 7.93; N, 2.60. Found, C, 66.45; H, 8.25; $\mathrm{N}, 2.70 .{ }^{1} \mathrm{H}$ NMR $\left(\mathrm{C}_{6} \mathrm{D}_{6}, 300 \mathrm{MHz}, 25^{\circ} \mathrm{C}\right): \delta=0.63\left(\mathrm{~d}, 9 \mathrm{H}, \mathrm{CH}\left(\mathrm{CH}_{3}\right)_{2}\right), 0.90\left(\mathrm{~d}, 9 \mathrm{H}, \mathrm{CH}\left(\mathrm{CH}_{3}\right)_{2}\right)$, 1.02 (d, 9H, $\left.\mathrm{CH}\left(\mathrm{CH}_{3}\right)_{2}\right), 1.16$ (d, 9H, $\left.\mathrm{CH}\left(\mathrm{CH}_{3}\right)_{2}\right), 1.19$ (s, 27H, $\left.\mathrm{CH}\left(\mathrm{CH}_{3}\right)_{2}\right), 1.38$ (m, 8H, THF), 1.60 (s, 27H, $\left.\mathrm{CH}\left(\mathrm{CH}_{3}\right)_{2}\right), 3.05$ (sept, 3H, $\left.\mathrm{CH}\left(\mathrm{CH}_{3}\right)_{2}\right), 3.48$ (m, 8H, THF), 3.79 (sept, 3H, $\left.\mathrm{CH}\left(\mathrm{CH}_{3}\right)_{2}\right), 5.45(\mathrm{~d}, 3 \mathrm{H}, \mathrm{CH}), 6.43(\mathrm{~d}, 3 \mathrm{H}, \mathrm{CH}), 7.21$ (br s, 1H, CH), 7.24 (br s, 1H, CH), 7.26 (m, $1 \mathrm{H}, \mathrm{CH})$.

Synthesis of [Th(dippap) 3 K $][K($ crypt)] (4-ap mono crypt). A $20 \mathrm{~mL}$ scintillation vial was charged with 4-ap $(0.100 \mathrm{~g}, 0.0628 \mathrm{mmol})$ and $3 \mathrm{~mL}$ toluene. A separate $20 \mathrm{~mL}$ scintillation vial was charged with 2,2,2-cryptand $(0.0236 \mathrm{~g}, 0.132 \mathrm{mmol})$, dissolved in $3 \mathrm{~mL}$ ether, and added dropwise to the stirring 4-ap solution. Precipitation of a golden yellow solid was observed. After stirring for 1 hour, the precipitate was filtered over a fine porosity frit and the resulting golden yellow solid was washed with ether $(10 \mathrm{~mL})$. Volatiles were removed in vacuo to afford a golden yellow powder $\left(0.056 \mathrm{~g}, 0.031 \mathrm{mmol}, 46 \%\right.$ yield), assigned as [Th( ${ }^{\text {dipp }}$ ap) $\left.{ }_{3} \mathrm{~K}\right][\mathrm{K}$ (crypt)] (4-ap Mono crypt). Light yellow, rod-shaped crystals suitable for X-ray analysis were grown from an ether solution of cryptand layered with a toluene solution of 4-ap (1:1 ratio) overnight in a narrow, sealed J-young tube at room temperature. Elemental analysis of $\mathrm{C}_{96} \mathrm{H}_{147} \mathrm{~N}_{5} \mathrm{O}_{9} \mathrm{~K}_{2}$ Th: calculated, C, 63.13; H, 8.12; N, 3.84. Found, C, 63.00; H, 8.15; N, 3.70. ${ }^{1} \mathrm{H}$ NMR (pyr-d5, $400 \mathrm{MHz}, 25{ }^{\circ} \mathrm{C}$ ): $\delta$ $=0.94,1.14,1.30,1.35,1.40,1.50,1.51,1.74,1.83,1.88,2.13,2.39\left(\mathrm{t}, 12 \mathrm{H}, \mathrm{OCH}_{2} \mathrm{CH}_{2} \mathrm{~N}\right), 3.39$ $\left(\mathrm{t}, 12 \mathrm{H}, \mathrm{OCH}_{2} \mathrm{CH}_{2} \mathrm{~N}\right), 3.43\left(\mathrm{~s}, 12 \mathrm{H}, \mathrm{OCH}_{2} \mathrm{CH}_{2} \mathrm{~N}\right), 3.67,6.08,6.52,7.29,7.47$. Note that ligand peaks cannot be conclusively assigned or integrated due to the large intensity of cryptand peaks overwhelming the ligand peaks.

Synthesis of $\left[\mathbf{T h}\left({ }^{\text {dipp }} \mathbf{a p}\right)_{3}\right][\mathrm{K}(\mathbf{c r y p t})]_{2}$ (4-ap crypt). A $20 \mathrm{~mL}$ scintillation vial was charged with 4-ap $(0.100 \mathrm{~g}, 0.0628 \mathrm{mmol})$ and $3 \mathrm{~mL}$ THF. A separate $20 \mathrm{~mL}$ scintillation vial was charged with 2,2,2-cryptand (0.0496 g, $0.132 \mathrm{mmol})$, dissolved in $3 \mathrm{~mL}$ THF, and added dropwise to the stirring 4-ap solution. Darkening of the solution was observed. After 1 hour, volatiles were removed in vacuo. The crude mixture was washed with ether $(2 \times 5 \mathrm{~mL})$ to afford a golden yellow powder $(0.122 \mathrm{~g}, 0.055 \mathrm{mmol}, 88 \%$ yield $)$, assigned as [Th( $\left.\left.{ }^{\mathrm{dipp}} \mathrm{ap}\right)_{3}\right][\mathrm{K}(\mathrm{crypt})]_{2}$ (4-ap crypt). Yellow, block-shaped crystals suitable for X-ray analysis were grown from a THF solution layered with pentane (1:1 ratio) overnight in a narrow, sealed J-young tube at room temperature. Elemental analysis of $\mathrm{C}_{114} \mathrm{H}_{183} \mathrm{~N}_{7} \mathrm{O}_{15} \mathrm{~K}_{2}$ Th: calculated, C, 62.18; H, 8.38; N, 4.45. Found, C, 62.03; H, 8.55; $\mathrm{N}, 4.40 .{ }^{1} \mathrm{H}$ NMR (pyr-d5, $\left.300 \mathrm{MHz}, 25{ }^{\circ} \mathrm{C}\right): \delta=0.96,1.14,1.29,1.41,1.51,1.88,2.20,2.38(\mathrm{t}$, $\left.12 \mathrm{H}, \mathrm{OCH}_{2} \mathrm{CH}_{2} \mathrm{~N}\right), 3.38\left(\mathrm{t}, 12 \mathrm{H}, \mathrm{OCH}_{2} \mathrm{CH}_{2} \mathrm{~N}\right), 3.43\left(\mathrm{~s}, 12 \mathrm{H}, \mathrm{OCH}_{2} \mathrm{CH}_{2} \mathrm{~N}\right), 3.65,4.62,4.87,5.60$, $6.11,6.57,7.35,7.46$. Note that ligand peaks cannot be conclusively assigned or integrated due to the large intensity of cryptand peaks overwhelming the ligand peaks.

Synthesis of Th(dippap)2(OPPh)3 (5-ap). A $20 \mathrm{~mL}$ scintillation vial was charged with 4ap $(0.100 \mathrm{~g}, 0.0628 \mathrm{mmol})$ and $3 \mathrm{~mL}$ THF. A separate $20 \mathrm{~mL}$ scintillation vial was charged with 
$\mathrm{OPPh}_{3}(0.0349 \mathrm{~g}, 0.126 \mathrm{mmol})$, dissolved in $3 \mathrm{~mL}$ THF, and added dropwise to the stirring 4-ap solution. After 1 hour, volatiles were removed in vacuo. The crude mixture was washed with pentane $(2 \times 5 \mathrm{~mL})$ to afford a yellow solid. The crude mixture was recrystallized from a 2:1 ether: pentane mixture with a few drops of THF ( $0.064 \mathrm{~g}, 0.0413 \mathrm{mmol}, 23 \%$ yield $)$ and was assigned as $\mathrm{Th}\left({ }^{\mathrm{dipp}} \mathrm{ap}_{2}(\mathrm{OPPh})_{3}(\right.$ 5-ap). Yellow, rod-shaped crystals suitable for $\mathrm{X}$-ray analysis were grown from a concentrated ether solution at $-35^{\circ} \mathrm{C}$. Elemental analysis of $\mathrm{C}_{88} \mathrm{H}_{104} \mathrm{~N}_{2} \mathrm{O}_{4} \mathrm{P}_{2} \mathrm{Th}$ : calculated, $\mathrm{C}, 68.29 ; \mathrm{H}, 6.77 ; \mathrm{N}, 1.81$. Found, $\mathrm{C}, 67.82 ; \mathrm{H}, 7.00 ; \mathrm{N}, 1.91 .{ }^{1} \mathrm{H} \mathrm{NMR}\left(\mathrm{C}_{6} \mathrm{D}_{6}, 400 \mathrm{MHz}, 2{ }^{\circ} \mathrm{C}\right)$ : 0.46 (br m, 12H, $\left.\mathrm{CH}\left(\mathrm{CH}_{3}\right)_{2}\right), 1.11$ (br m, $\left.12 \mathrm{H}, \mathrm{CH}\left(\mathrm{CH}_{3}\right)_{2}\right), 1.41$ (s, $\left.18 \mathrm{H}, \mathrm{C}\left(\mathrm{CH}_{3}\right)_{3}\right), 1.56$ (s, $18 \mathrm{H}$, $\left.\mathrm{C}\left(\mathrm{CH}_{3}\right)_{3}\right), 3.31$ (br m, 2H, $\left.\mathrm{CH}\left(\mathrm{CH}_{3}\right)_{2}\right), 4.19$ (br m, 2H, $\left.\mathrm{CH}\left(\mathrm{CH}_{3}\right)_{2}\right), 5.49$ (br m, 2H, $\left.\mathrm{CH}\right), 6.82$ (d, $2 \mathrm{H}, \mathrm{CH}), 6.91\left(\mathrm{~m}, 12 \mathrm{H}, \mathrm{OPPh}_{3}\right), 7.05\left(\mathrm{~m}, 12 \mathrm{H}, \mathrm{OPPh}_{3}\right), 7.13(\mathrm{~m}, 3 \mathrm{H}, \mathrm{CH}), 7.20\left(\mathrm{br} \mathrm{m}, 6 \mathrm{H}, \mathrm{OPPh}_{3}\right)$. ${ }^{31} \mathrm{P}$ NMR $\left(\mathrm{C}_{6} \mathrm{D}_{6}, 400 \mathrm{MHz}, 25^{\circ} \mathrm{C}\right): 47.08\left(\mathrm{OPPh}_{3}\right)$. 


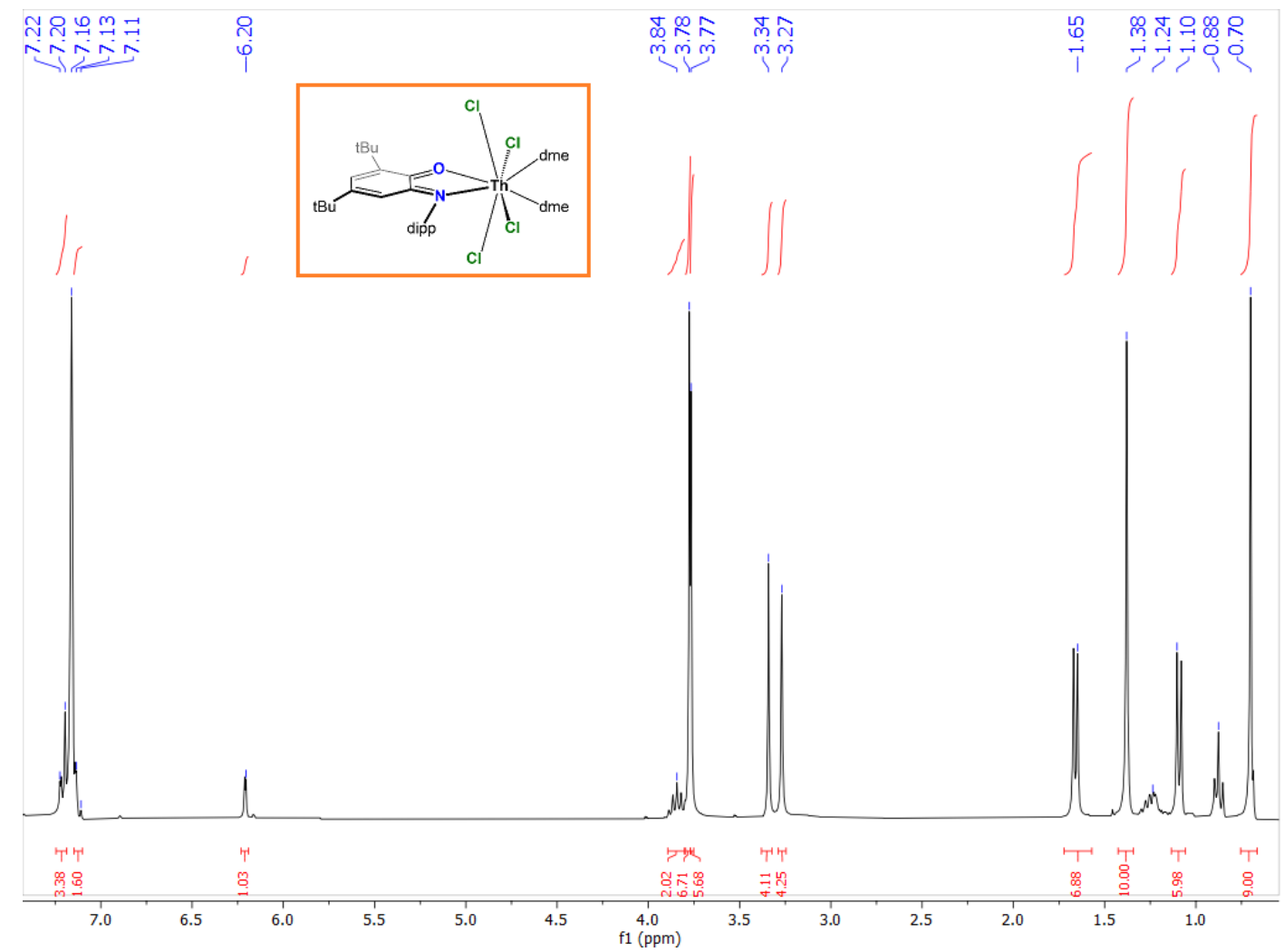

Figure S1. ${ }^{1} \mathrm{H}$ NMR spectrum of 1-iq (Benzene- $d_{6}, 25^{\circ} \mathrm{C}$ ).

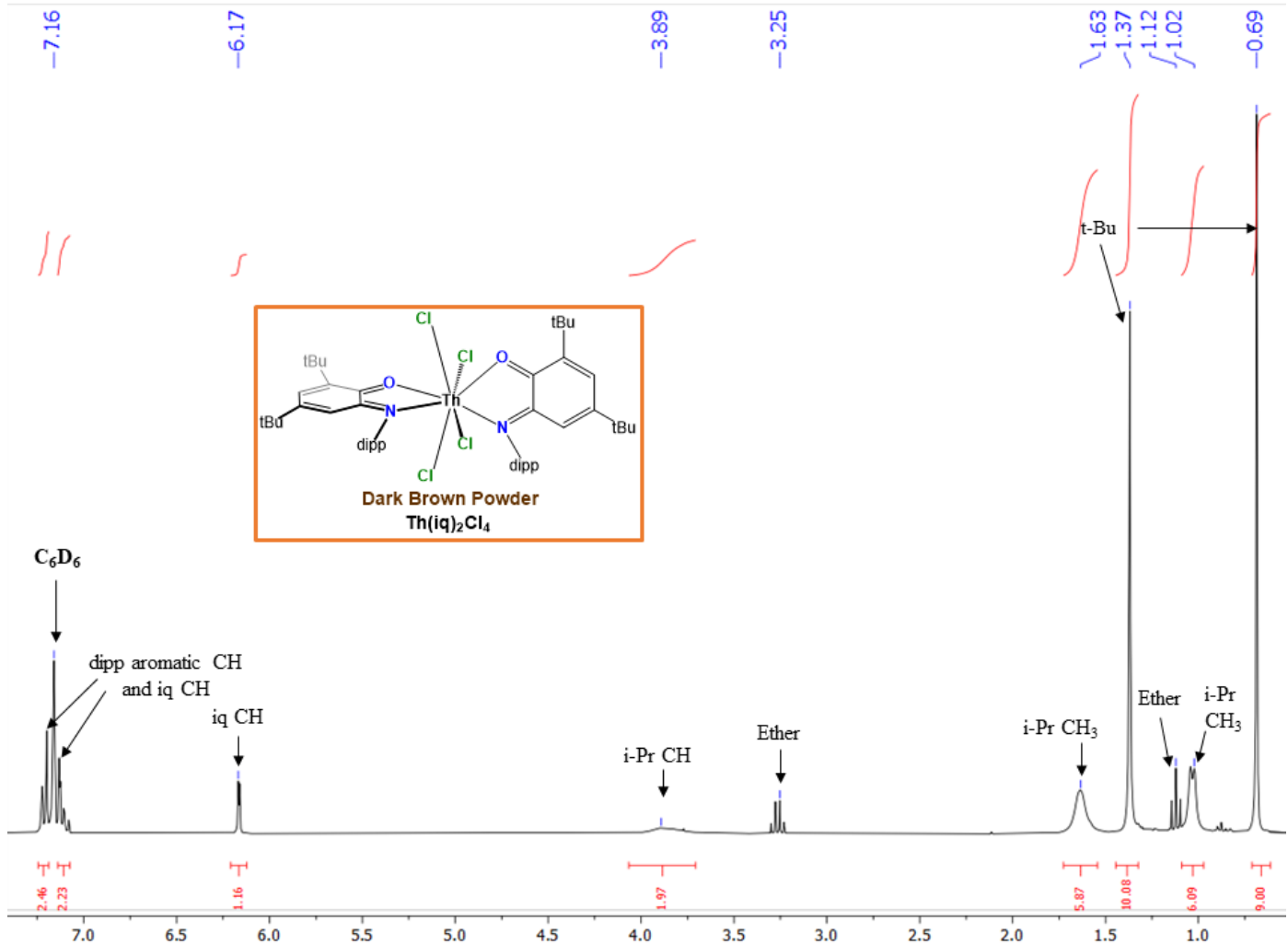

Figure S2. ${ }^{1} \mathrm{H}$ NMR spectrum of 2-iq (Benzene- $d_{6}, 25{ }^{\circ} \mathrm{C}$ ). 


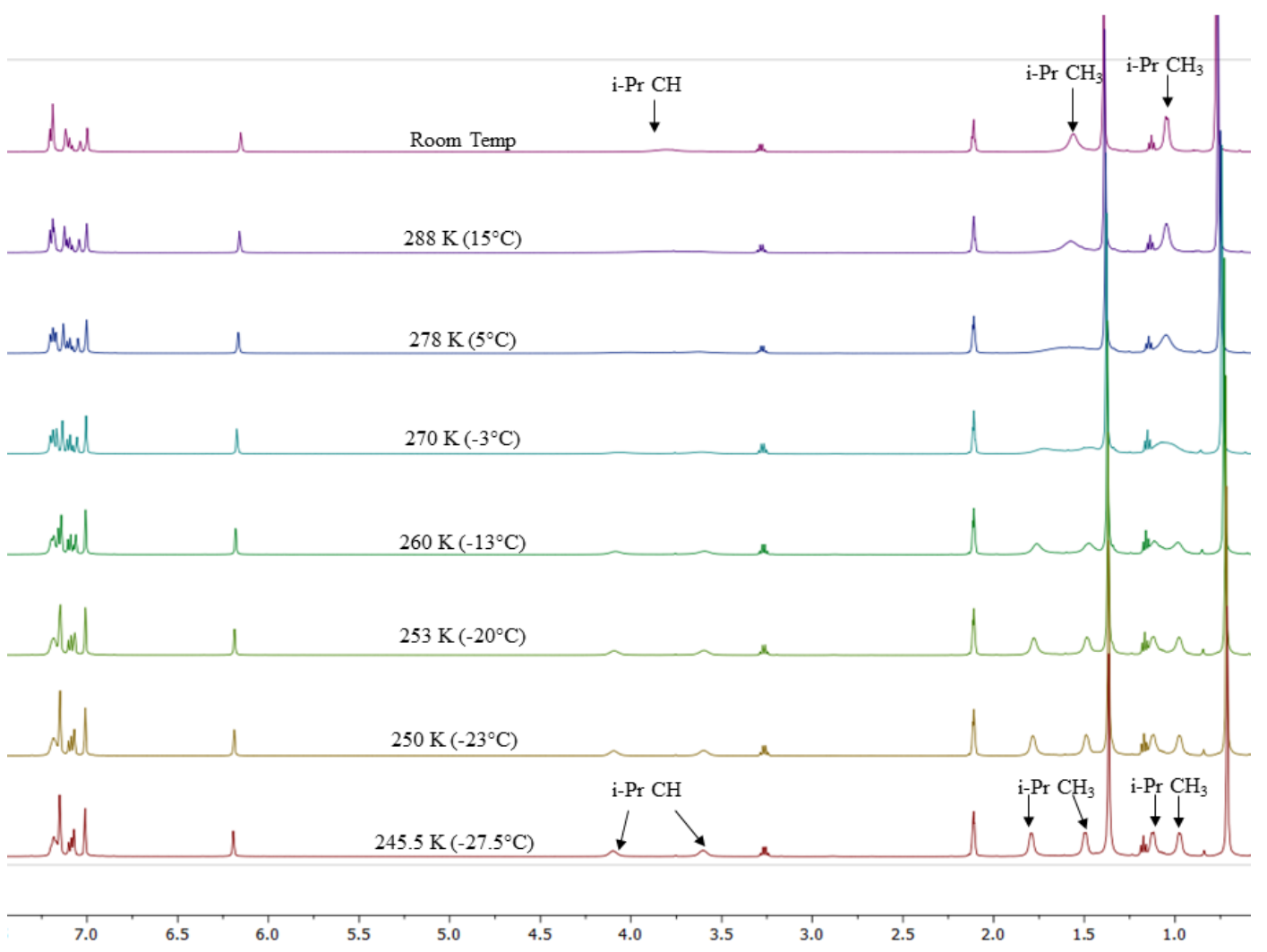

Figure S3. Variable temperature ${ }^{1} \mathrm{H}$ NMR spectrum of 2-iq (Toluene- $d_{8}$, VT).
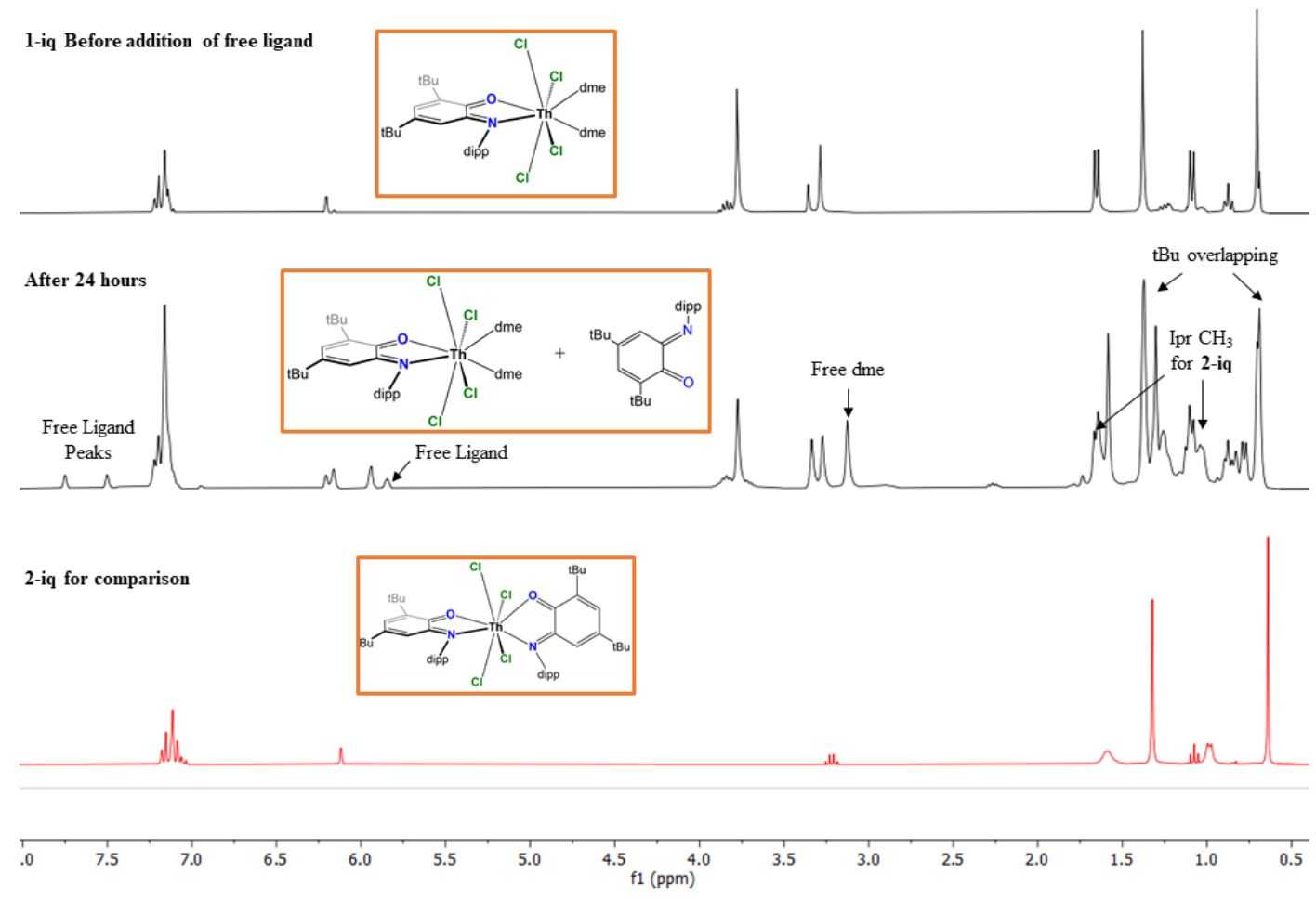

Figure S4. NMR tube reaction of addition of 1 equiv. of dippiq to 1-iq (Benzene- $d_{6}, 25^{\circ} \mathrm{C}$ ). 


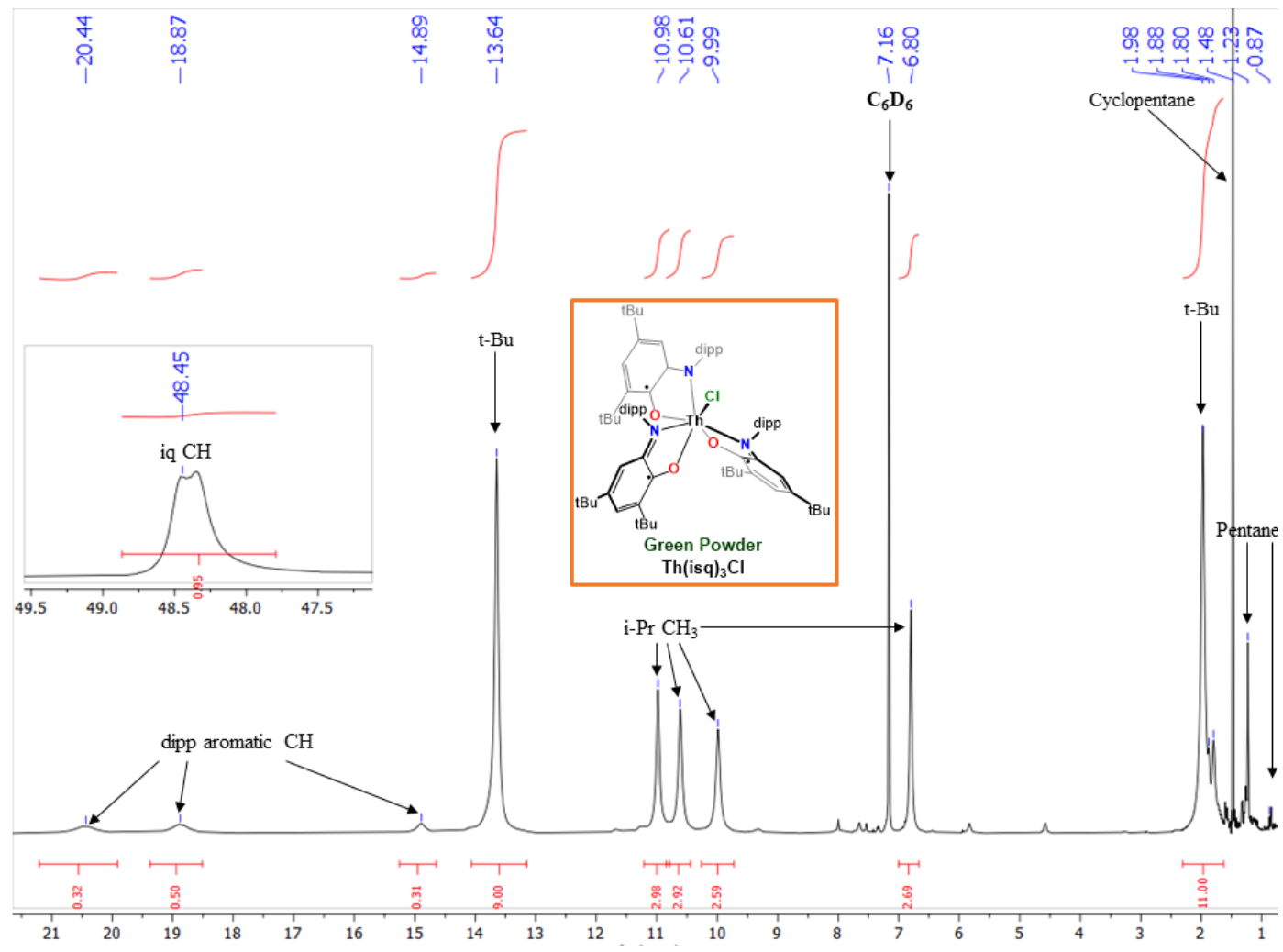

Figure S5. ${ }^{1} \mathrm{H}$ NMR spectrum of 3-isq (Benzene- $d_{6}, 25^{\circ} \mathrm{C}$ ).
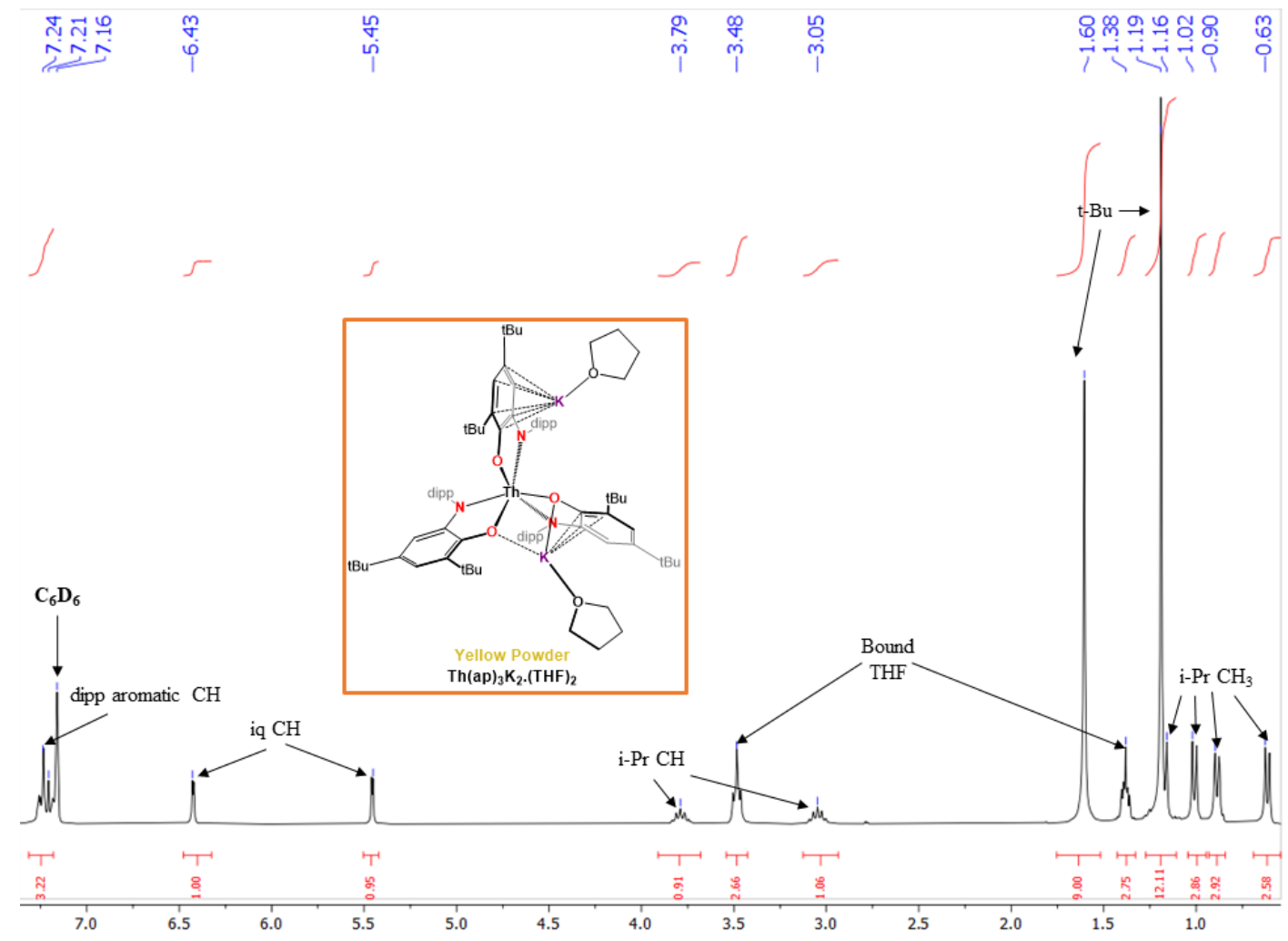

Figure S6. ${ }^{1} \mathrm{H}$ NMR spectrum of 4-ap (Benzene- $d_{6}, 25^{\circ} \mathrm{C}$ ). 

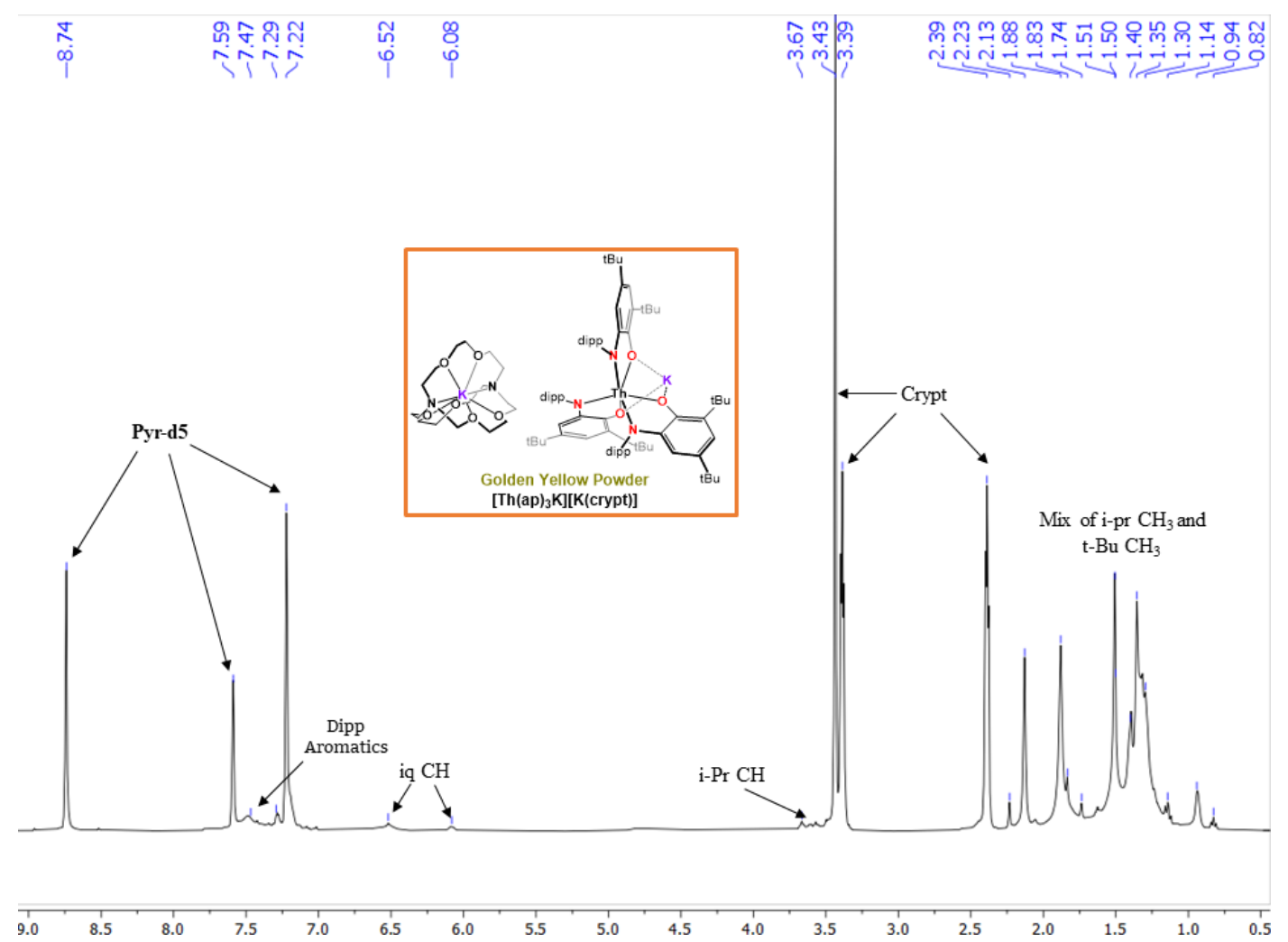

Figure S7. ${ }^{1} \mathrm{H}$ NMR spectrum of 4-ap mono crypt (Pyridine- $d_{5}, 25{ }^{\circ} \mathrm{C}$ ).
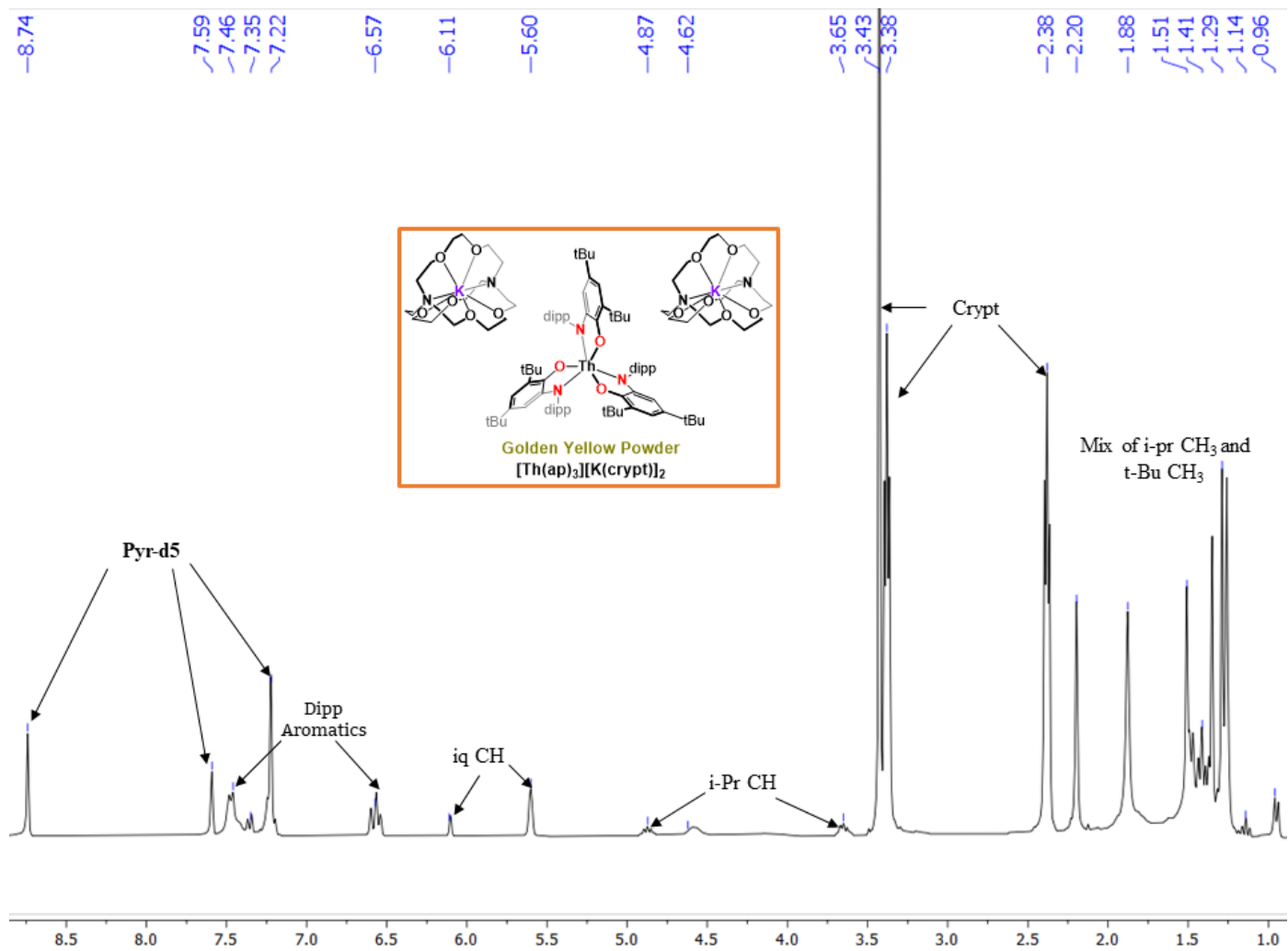

Figure S8. ${ }^{1} \mathrm{H}$ NMR spectrum of 4-ap crypt (Pyridine- $d_{5}, 25^{\circ} \mathrm{C}$ ). 


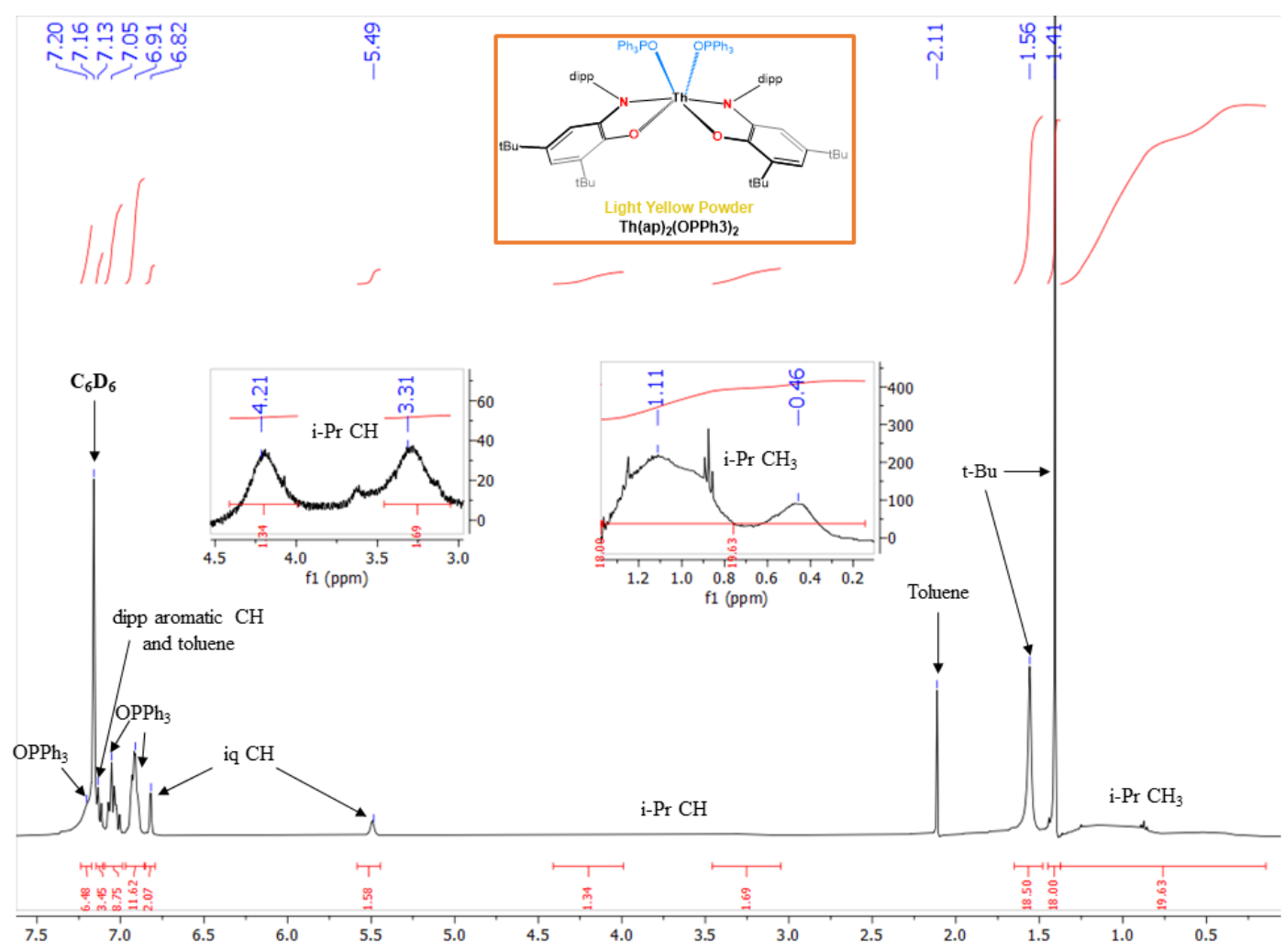

Figure S9. ${ }^{1} \mathrm{H}$ NMR spectrum of 5-ap (Benzene- $d_{6}, 25^{\circ} \mathrm{C}$ ).
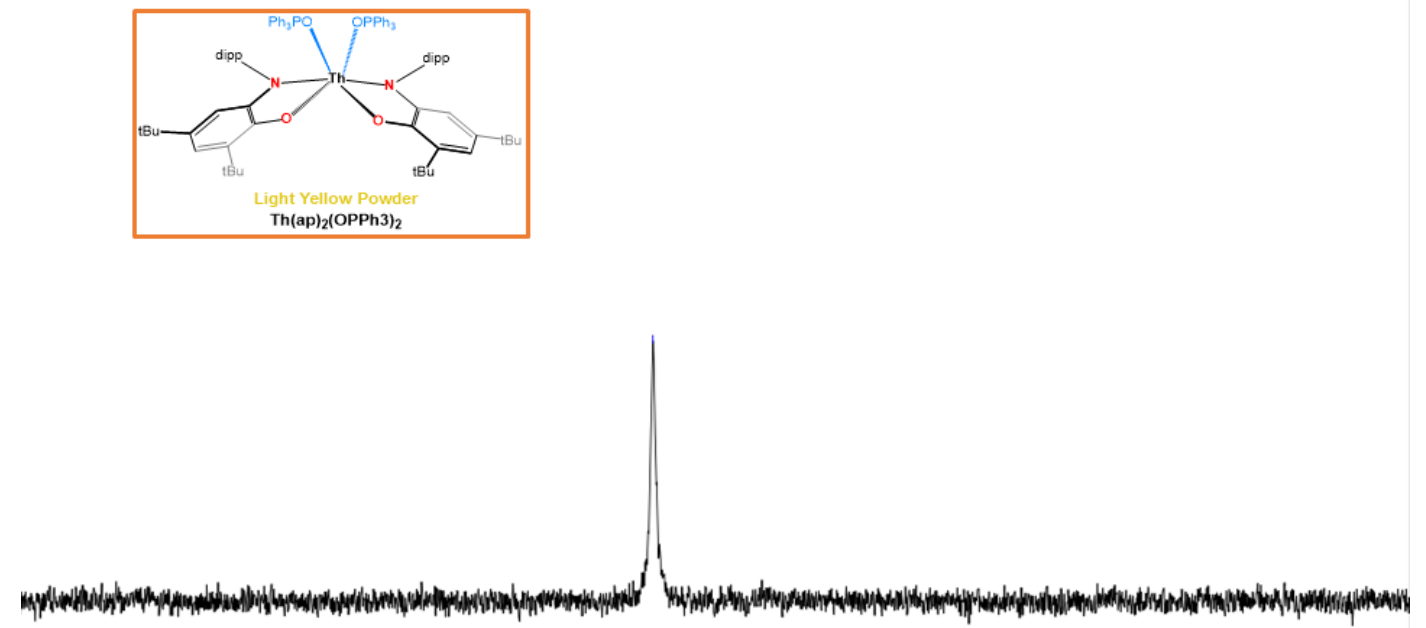

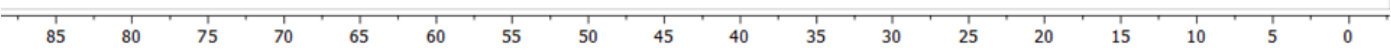

Figure S10. ${ }^{31} \mathrm{P}$ NMR spectrum of 5-ap (Benzene- $d_{6}, 25{ }^{\circ} \mathrm{C}$ ). 


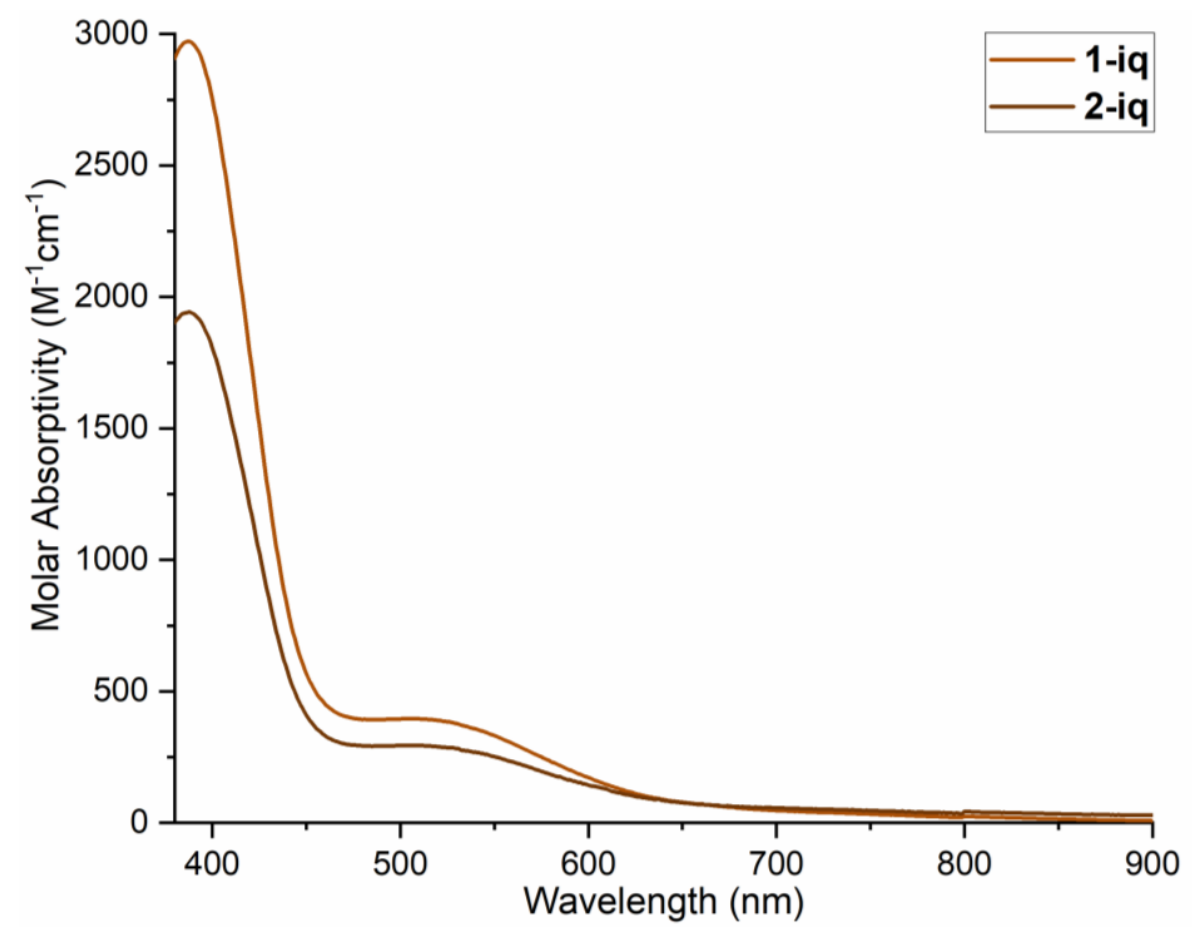

Figure S11. Electronic absorption spectra (UV-Vis region) of 1-iq and 2-iq (for comparison) recorded in $\mathrm{THF}$ at $25^{\circ} \mathrm{C}$.

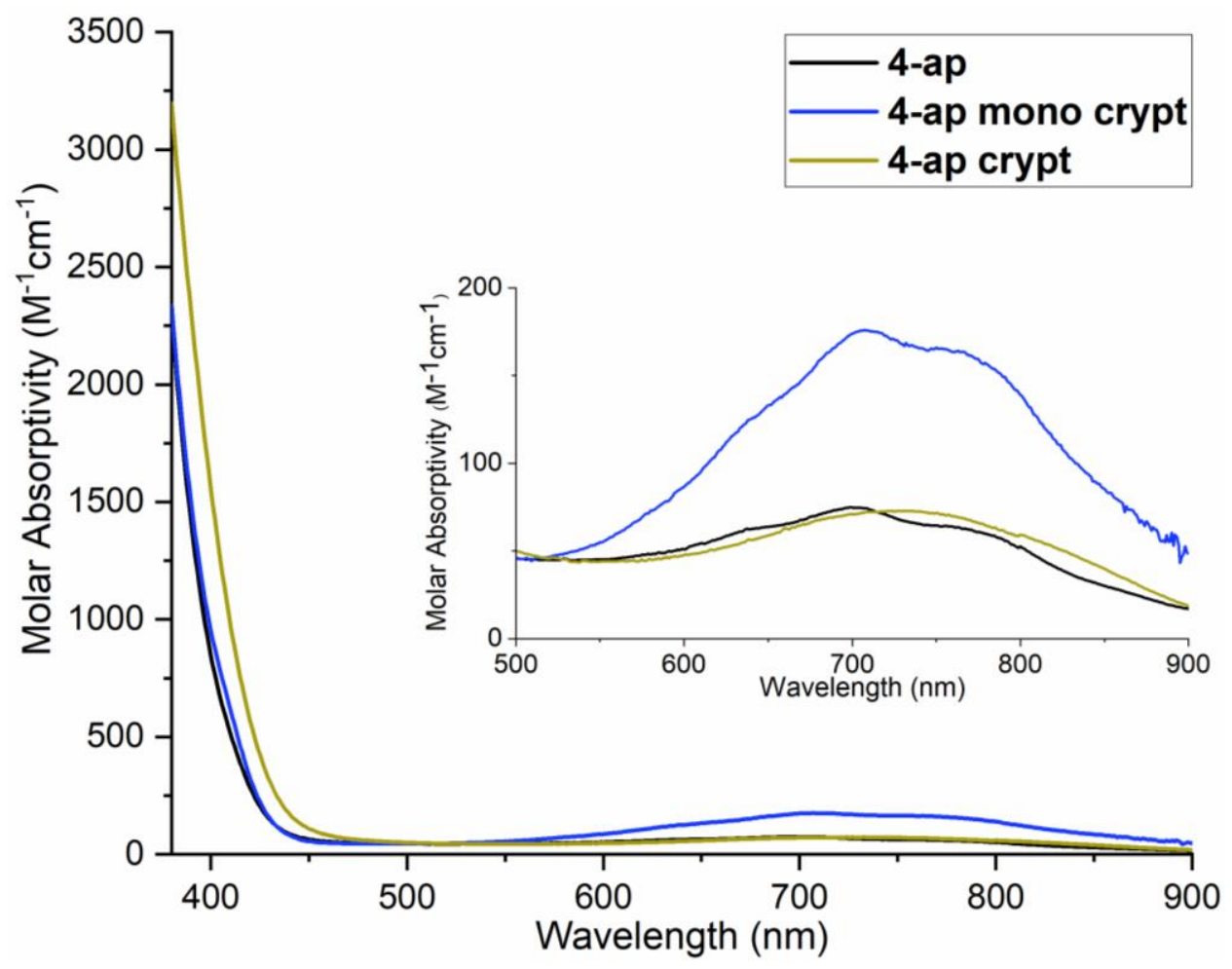

Figure S12. Electronic absorption spectra (UV-Vis region) of 4-ap, 4-ap mono crypt and 4-ap crypt (for comparison) recorded in THF at $25^{\circ} \mathrm{C}$. 


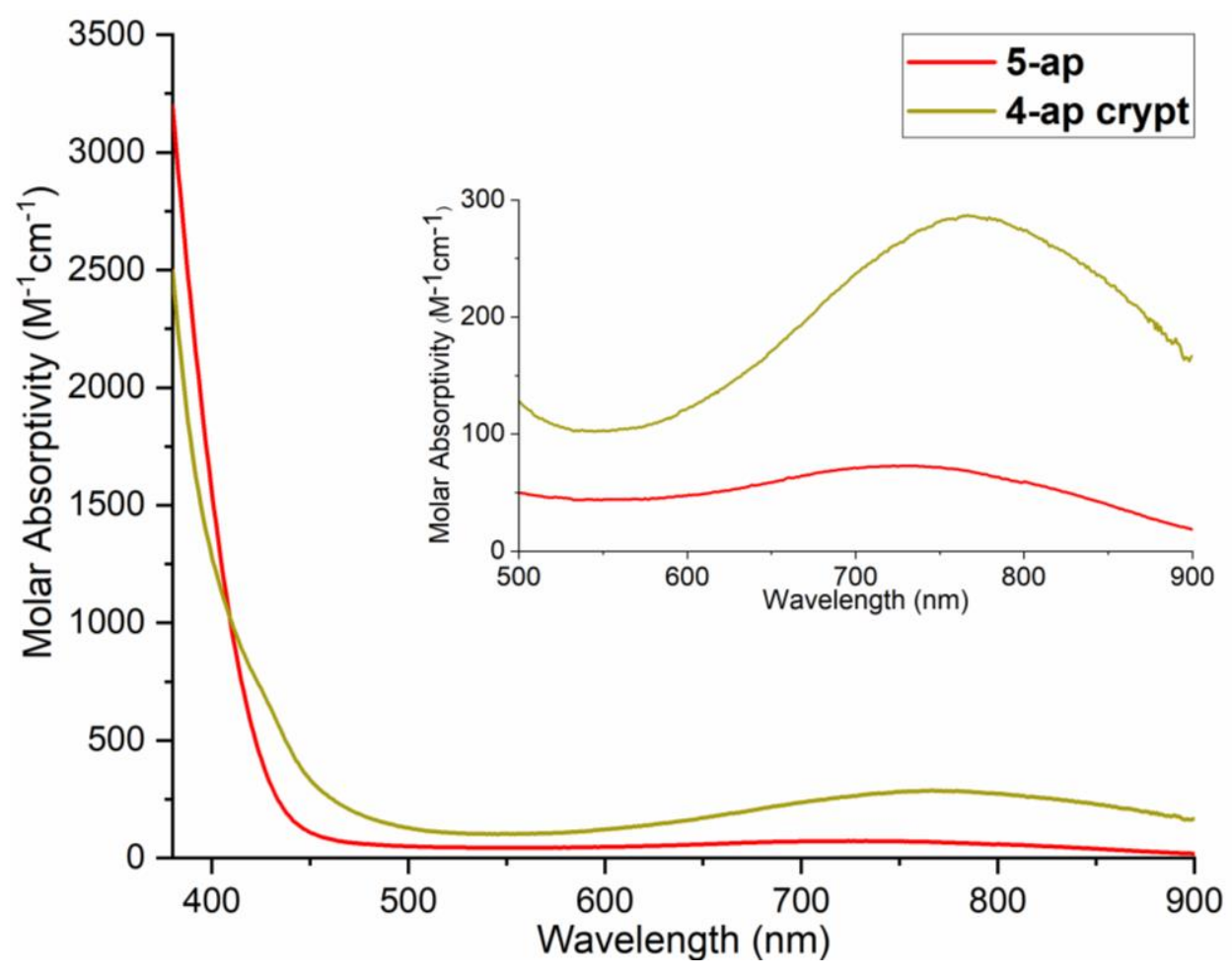

Figure S13. Electronic absorption spectra (UV-Vis region) of 5-ap and 4-ap crypt (for comparison) recorded in THF at $25^{\circ} \mathrm{C}$.

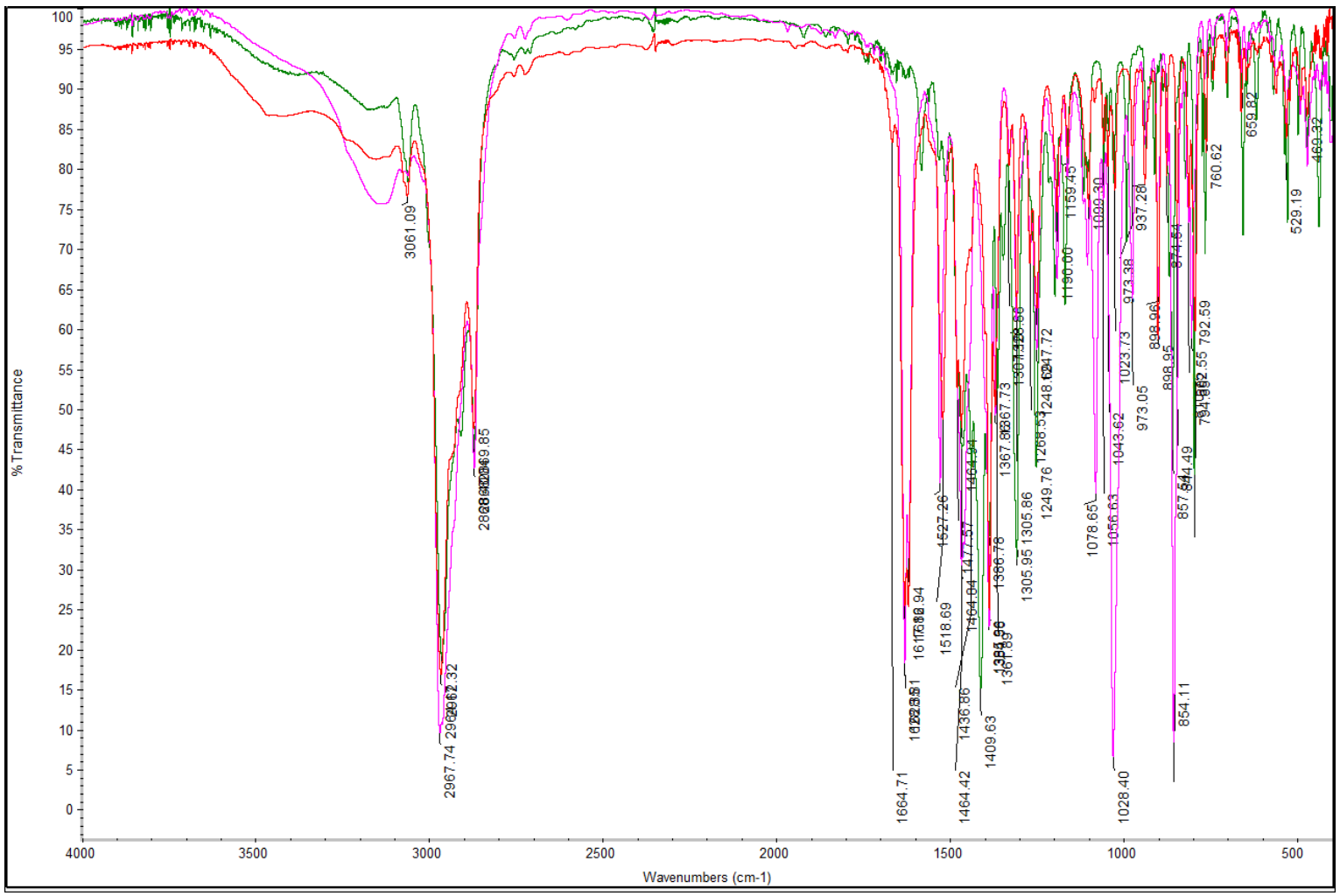

Figure S14. IR Spectra (KBr pellet) of 1-iq (pink), 2-iq (red), and 3-isq (green). 


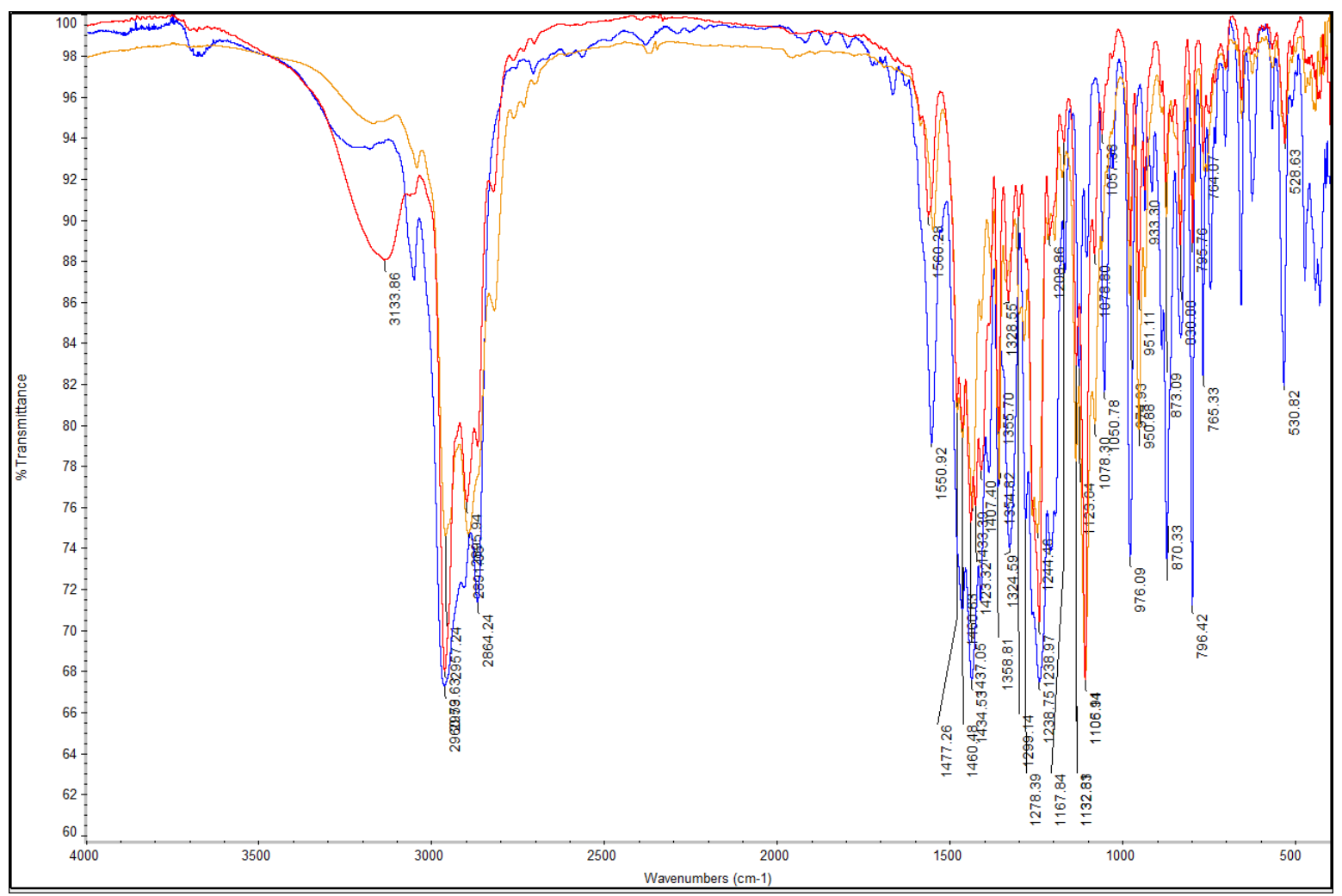

Figure S15. IR Spectra (KBr pellet) of 4-ap (blue), 4-ap mono crypt (red), and 4-ap $\operatorname{crypt}($ orange).

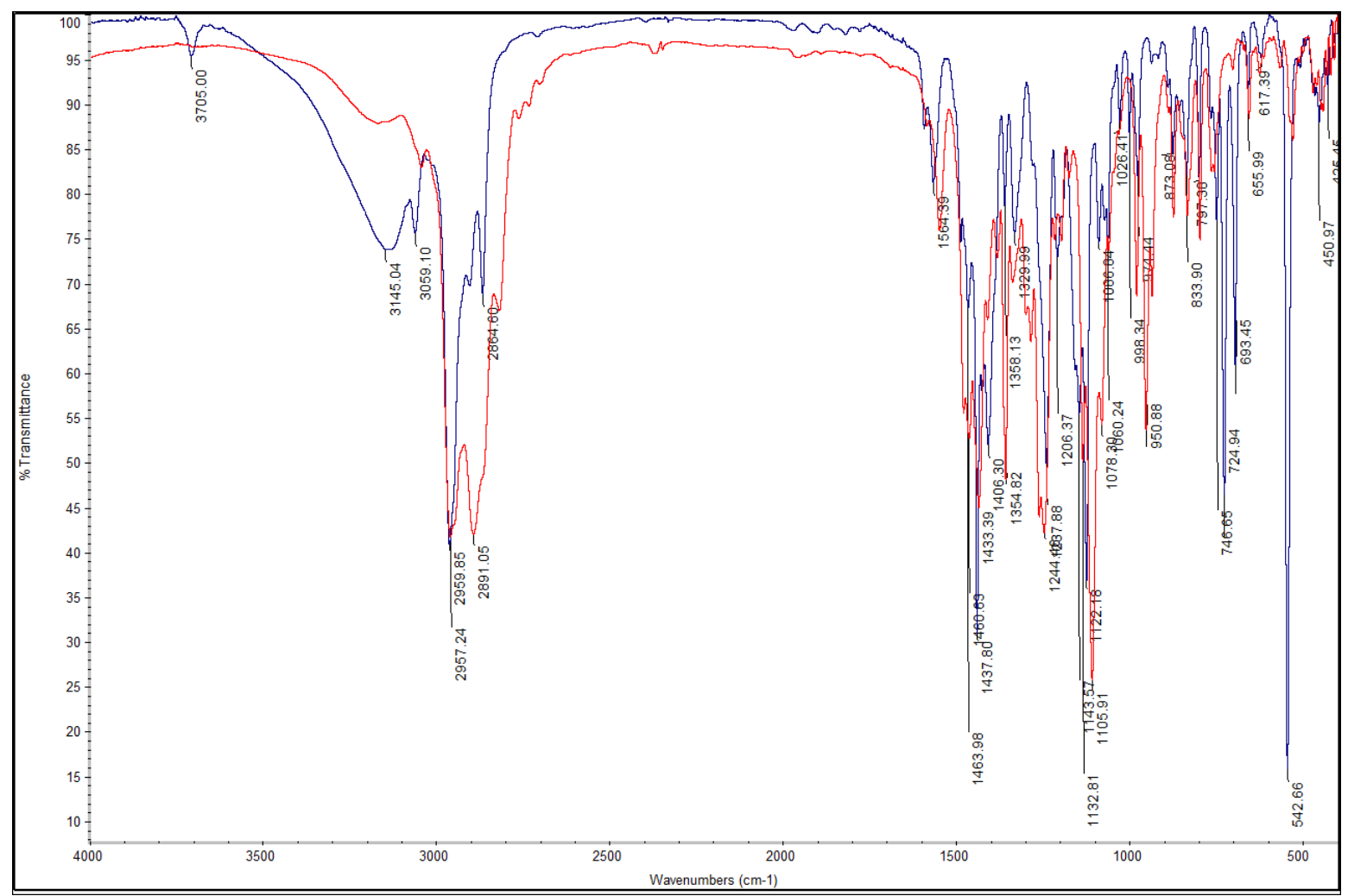

Figure S16. IR Spectra (KBr pellet) of 5-ap (blue) and 4-ap crypt (red) for comparison. 

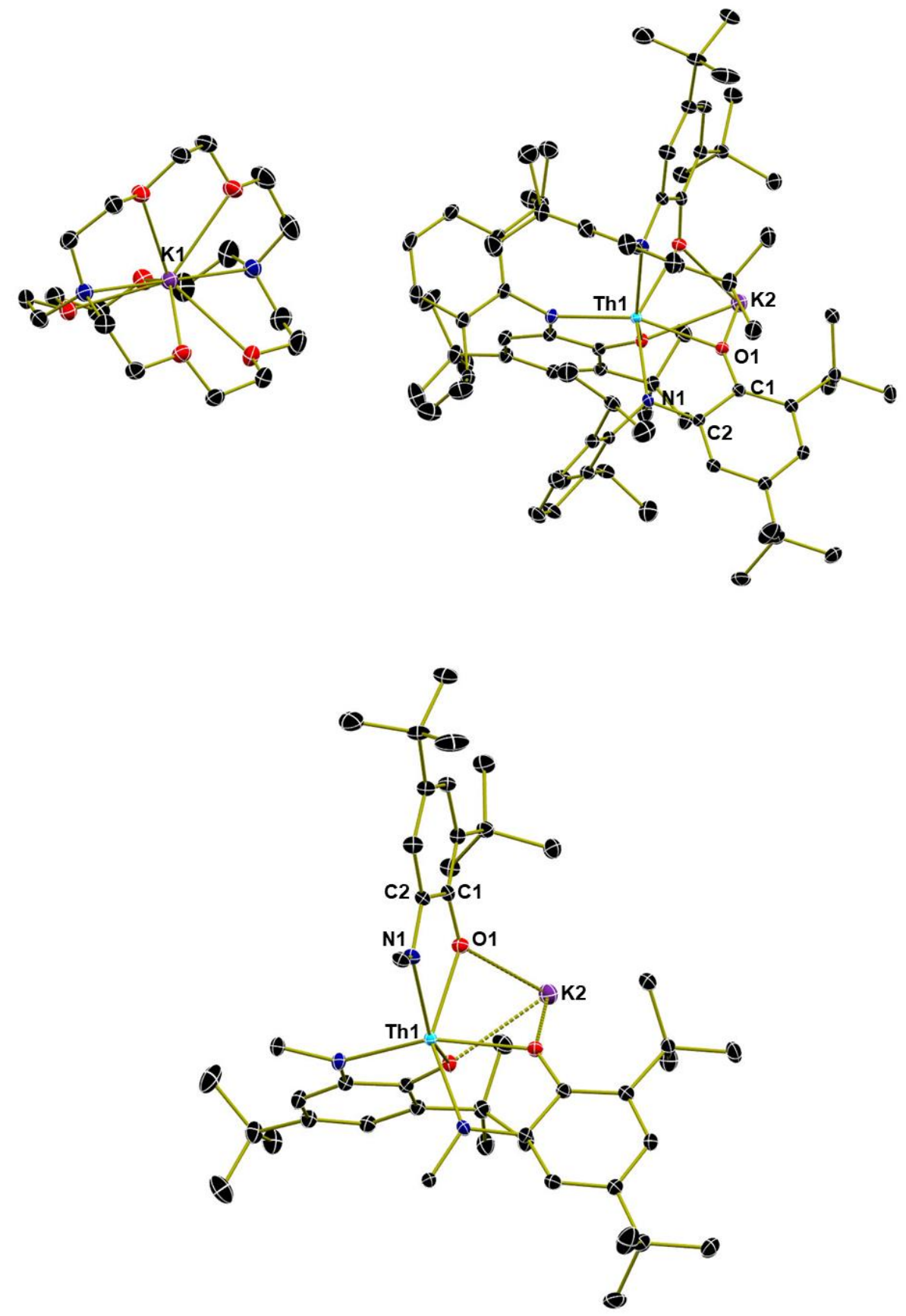

Figure S17. Molecular structure of 4-ap mono crypt with (top) and without (bottom) dipp groups and encapsulated potassium ion shown with $30 \%$ probability ellipsoids. Hydrogen atoms and cocrystallized solvent molecules are omitted for clarity. 

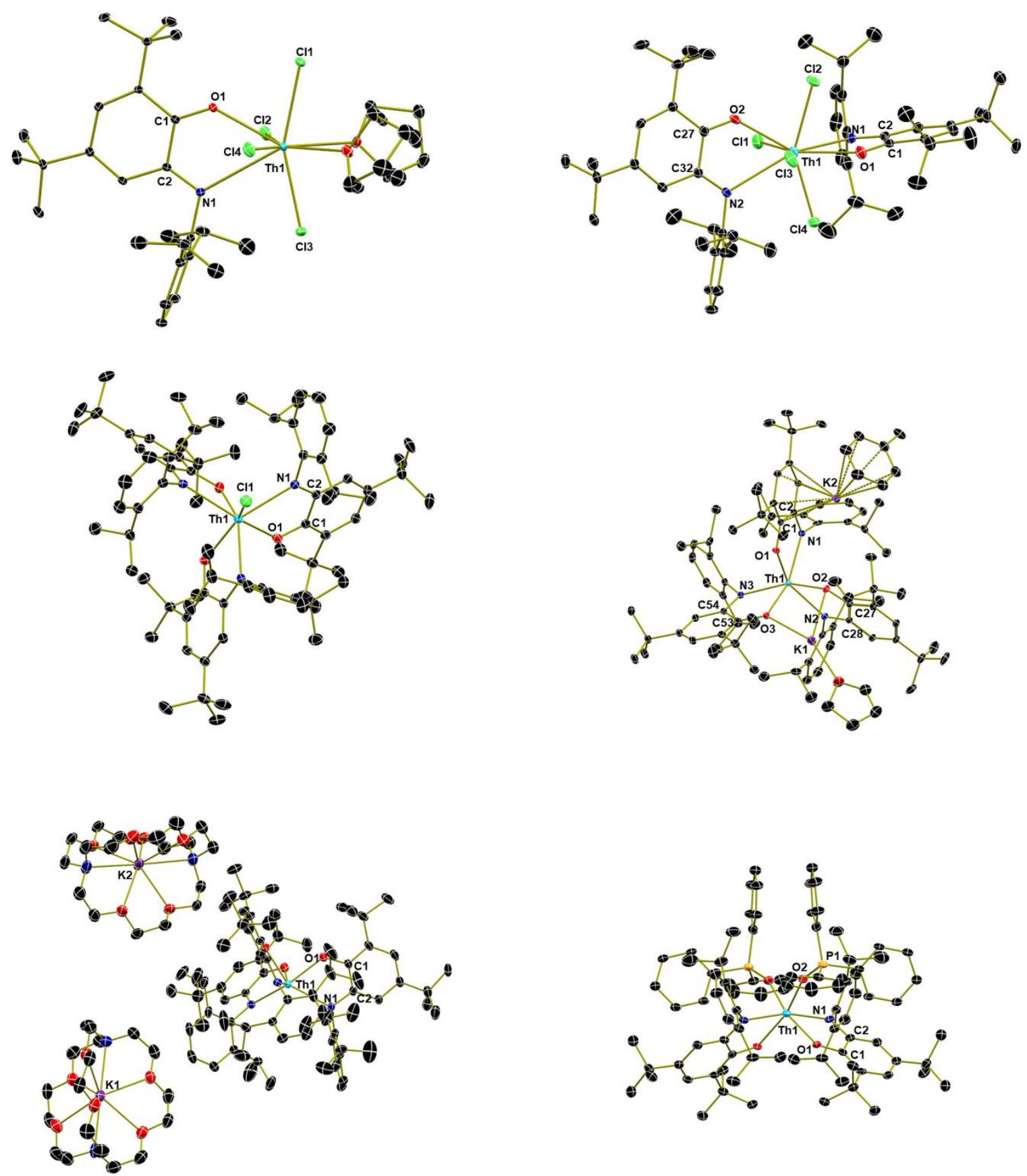

Figure S18. Molecular structures of 1-iq (top left), 2-iq (top right), 3-isq (center left), 4-ap (center right), 4-ap crypt (bottom left) and 5-ap (bottom right) shown with 30\% probability ellipsoids. Hydrogen atoms and cocrystallized solvent molecules are omitted for clarity. 


\section{General Magnetometry Details}

Magnetic susceptibility and magnetization data were collected using a Quantum Design MPMS-7 SQUID magnetometer. Samples were prepared in a $\mathrm{N}_{2}$ filled glovebox (Vacuum Atmospheres, Inc. Nexus II) under inert conditions. Powdered samples of 3-isq were loaded into polyethylene bags and these bags were subsequently sealed using a Ziploc v159 Vacuum Sealer System. The bags were then removed from the glovebox, folded, inserted and immobilized in a plastic drinking straw. Reproducibility of the magnetic susceptibility data was checked over two separate batches for 3-isq. Ferromagnetic impurities were checked through variable field analyses $(0$ to $20 \mathrm{kOe})$ of magnetization at $100 \mathrm{~K}$. Saturation of magnetization measurements were performed at $2 \mathrm{~K}$ varying the applied field from 0 to $70 \mathrm{kOe}$. Magnetic susceptibility data were collected at temperatures ranging from 2 to $300 \mathrm{~K}$ at an applied field of 10000 Oe. Data were corrected for the diamagnetic contributions of the sample holder and bag by subtracting empty containers; corrections for the sample were calculated from Pascal's constants.

Alternative, isosceles triangle spin coupling model. A comparable simulation to that described in the main text was attained with $S_{I}=S_{2}=S_{3}=1 / 2, \mathrm{~g}=2.0$ and two exchange coupling constants $J_{l}=-27.8 \mathrm{~cm}^{-1}$ and $J_{2}=-14.2 \mathrm{~cm}^{-1}$ using the PHI fitting program, based on the following spin Hamiltonian:

$$
\widehat{H}=-2 J_{1}\left(\hat{S}_{1} \hat{S}_{2}+\hat{S}_{1} \hat{S}_{3}\right)-2 J_{2}\left(\hat{S}_{2} \hat{S}_{3}\right)
$$
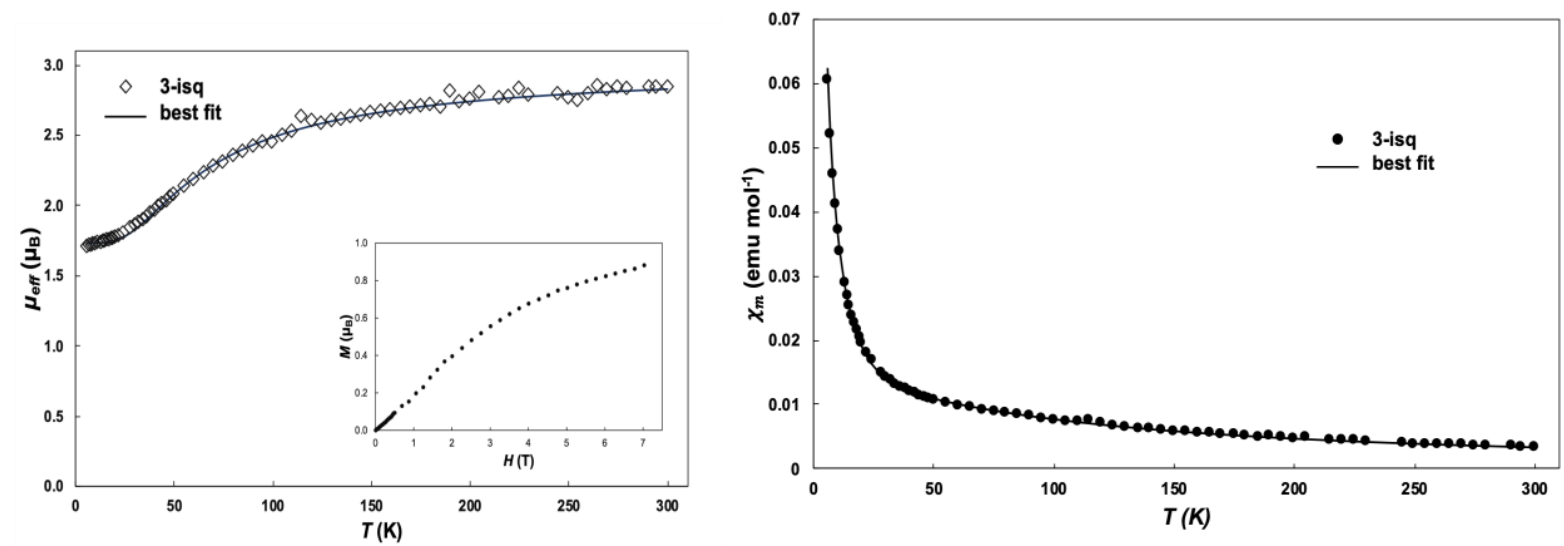

Figure S19. Plot of $\mu_{\text {eff }}$ versus $\mathrm{T}$ for 3-isq with inset of field dependent data of $M$ versus $H$ (left) collected at $2 \mathrm{~K}$. Magnetic susceptibility plot, $\chi_{\mathrm{m}}$ versus $\mathrm{T}$ (right). Solid lines represent least squares fitting of the data using a triangular geometry with two $J$ values, where $J_{l}=-27.8 \mathrm{~cm}^{-1}$ and $J_{2}=-14.2 \mathrm{~cm}^{-1}$ (see text). 


\section{General Crystallographic Details}

Single crystals of of 1-iq, 2-iq, 3-isq, 4-ap, 4-ap mono crypt, and 4-ap crypt, were coated with poly(isobutylene) oil and quickly transferred to the goniometer head of a Bruker Quest diffractometer with a fixed chi angle, a sealed tube fine focus X-ray tube, single crystal curved graphite incident beam monochromator, a Photon100 CMOS area detector and an Oxford Cryosystems low temperature device. Examination and data collection were performed with Mo Ko radiation $(\lambda=0.71073 \AA)$ at $150 \mathrm{~K}$.

Single crystals of 5-ap were coated with poly(isobutylene) oil and quickly transferred to the goniometer head of a Bruker Quest diffractometer with kappa geometry, an I- $\mu$-S microsource Xray tube, laterally graded multilayer (Goebel) mirror single crystal for monochromatization, a Photon-II CMOS area detector and an Oxford Cryosystems low temperature device. Examination and data collection were performed with $\mathrm{Cu} \mathrm{K} \alpha$ radiation $(\lambda=1.54178 \AA)$ at $150 \mathrm{~K}$.

Data were collected, reflections were indexed and processed, and the files scaled and corrected for absorption using APEX3 [1]. The space groups were assigned, and the structures were solved by direct methods using XPREP within the SHELXTL suite of programs [2] and refined by full matrix least squares against $\mathrm{F}^{2}$ with all reflections using Shelxl2018 [3] using the graphical interface Shelxle [4]. If not specified otherwise $\mathrm{H}$ atoms attached to carbon were positioned geometrically and constrained to ride on their parent atoms. $\mathrm{C}-\mathrm{H}$ bond distances were constrained to $0.95 \AA$ for aromatic and alkene $\mathrm{C}-\mathrm{H}$ and $\mathrm{CH}_{2}$ and alkyne $\mathrm{C}-\mathrm{H}$ moieties, and to $1.00,0.99$ and $0.98 \AA$ for aliphatic $\mathrm{C}-\mathrm{H}, \mathrm{CH}_{2}$ and $\mathrm{CH}_{3}$ moieties, respectively. Methyl $\mathrm{CH}_{3}$ atoms were allowed to rotate but not to tip to best fit the experimental electron density. $\mathrm{U}_{\text {iso }}(\mathrm{H})$ values were set to a multiple of $\mathrm{U}_{\mathrm{eq}}(\mathrm{C})$ with 1.5 for $\mathrm{CH}_{3}$, and 1.2 for $\mathrm{C}-\mathrm{H}$ and $\mathrm{CH}_{2}$ units, respectively. 
Local Name: RR2080_0m_final

CCDC: 2038474

Table S1. Crystallographic details for 1-iq

\begin{tabular}{|c|c|}
\hline \multicolumn{2}{|l|}{ Crystal data } \\
\hline Chemical formula & $\mathrm{C}_{34} \mathrm{H}_{53} \mathrm{Cl}_{4} \mathrm{NO}_{3} \mathrm{Th} \cdot \mathrm{C}_{4} \mathrm{H}_{10} \mathrm{O}$ \\
\hline$M_{\mathrm{r}}$ & 971.73 \\
\hline Crystal system, space group & Triclinic, $P \overline{1}$ \\
\hline Temperature $(\mathrm{K})$ & 150 \\
\hline$a, b, c(\AA)$ & $12.5945(7), 12.9321(7), 13.8085(8)$ \\
\hline$\alpha, \beta, \gamma\left({ }^{\circ}\right)$ & $103.403(2), 96.487(2), 97.026(2)$ \\
\hline$V\left(\AA^{3}\right)$ & $2148.0(2)$ \\
\hline$Z$ & 2 \\
\hline Radiation type & Mo $K \alpha$ \\
\hline$\mu\left(\mathrm{mm}^{-1}\right)$ & 3.76 \\
\hline Crystal size $(\mathrm{mm})$ & $0.66 \times 0.45 \times 0.37$ \\
\hline \multicolumn{2}{|l|}{ Data collection } \\
\hline Diffractometer & Bruker AXS D8 Quest CMOS diffractometer \\
\hline Absorption correction & $\begin{array}{l}\text { Multi-scan - SADABS 2016/2: Krause, L., Herbst-Irmer, R., } \\
\text { Sheldrick G.M. \& Stalke D. (2015). J. Appl. Cryst. 48, 3-10 }\end{array}$ \\
\hline$T_{\min ,}, T_{\max }$ & $0.492,0.747$ \\
\hline $\begin{array}{l}\text { No. of measured, independent and } \\
\text { observed }[I>2 \sigma(I)] \text { reflections }\end{array}$ & $43268,15175,13365$ \\
\hline$R_{\text {int }}$ & 0.030 \\
\hline$(\sin \theta / \lambda)_{\max }\left(\AA^{-1}\right)$ & 0.771 \\
\hline \multicolumn{2}{|l|}{ Refinement } \\
\hline$R\left[F^{2}>2 \sigma\left(F^{2}\right)\right], w R\left(F^{2}\right), S$ & $0.026,0.053,1.09$ \\
\hline No. of reflections & 15175 \\
\hline No. of parameters & 482 \\
\hline No. of restraints & 160 \\
\hline $\mathrm{H}$-atom treatment & $\mathrm{H}$-atom parameters constrained \\
\hline$\Delta \rho_{\max }, \Delta \rho_{\min }\left(\mathrm{e} \AA^{-3}\right)$ & $2.47,-1.72$ \\
\hline
\end{tabular}

Refinement Details: The two disordered THF moieties were restrained to have similar geometries. $\mathrm{U}^{\mathrm{ij}}$ components of ADPs for disordered atoms closer to each other than 2.0 Ångström were restrained to be similar. Subject to these conditions the occupancy ratio refined to 0.554(14) to $0.446(14)$.

Computer programs: Apex3 v2016.9-0 (Bruker, 2016), SAINT V8.37A (Bruker, 2016), SHELXS97 (Sheldrick, 2008), SHELXL2017/8 (Sheldrick, 2014), SHELXLE Rev714 (Hübschle et al., 2011). 
Local Name: RR34_0m_final

CCDC: 2038472

Table S2. Crystallographic details for 2-iq

\begin{tabular}{|c|c|}
\hline \multicolumn{2}{|l|}{ Crystal data } \\
\hline Chemical formula & $\mathrm{C}_{52} \mathrm{H}_{74} \mathrm{Cl}_{4} \mathrm{~N}_{2} \mathrm{O}_{2} \mathrm{Th} \cdot 2\left(\mathrm{CH}_{2} \mathrm{Cl}_{2}\right)$ \\
\hline$M_{\mathrm{r}}$ & 1302.82 \\
\hline Crystal system, space group & Triclinic, $P \overline{1}$ \\
\hline Temperature $(\mathrm{K})$ & 150 \\
\hline$a, b, c(\AA)$ & $11.2810(7), 11.8099(7), 23.8732(12)$ \\
\hline$\alpha, \beta, \gamma\left({ }^{\circ}\right)$ & $98.220(2), 97.178(2), 98.773(2)$ \\
\hline$V\left(\AA^{3}\right)$ & $3075.8(3)$ \\
\hline$Z$ & 2 \\
\hline Radiation type & Mo $K \alpha$ \\
\hline$\mu\left(\mathrm{mm}^{-1}\right)$ & 2.81 \\
\hline Crystal size $(\mathrm{mm})$ & $0.45 \times 0.11 \times 0.07$ \\
\hline \multicolumn{2}{|l|}{ Data collection } \\
\hline Diffractometer & Bruker AXS D8 Quest CMOS diffractometer \\
\hline Absorption correction & $\begin{array}{l}\text { Multi-scan - SADABS 2016/2: Krause, L., Herbst-Irmer, R., } \\
\text { Sheldrick G.M. \& Stalke D. (2015). J. Appl. Cryst. } 48 \text { 3-10. }\end{array}$ \\
\hline$T_{\min }, T_{\max }$ & $0.606,0.747$ \\
\hline $\begin{array}{l}\text { No. of measured, independent and } \\
\text { observed }[I>2 \sigma(I)] \text { reflections }\end{array}$ & $89585,33180,22704$ \\
\hline$R_{\text {int }}$ & 0.066 \\
\hline$(\sin \theta / \lambda)_{\max }\left(\AA^{-1}\right)$ & 0.785 \\
\hline \multicolumn{2}{|l|}{ Refinement } \\
\hline$R\left[F^{2}>2 \sigma\left(F^{2}\right)\right], w R\left(F^{2}\right), S$ & $0.061,0.102,1.06$ \\
\hline No. of reflections & 33180 \\
\hline No. of parameters & 731 \\
\hline No. of restraints & 366 \\
\hline H-atom treatment & H-atom parameters constrained \\
\hline$\Delta \rho_{\max }, \Delta \rho_{\min }\left(\mathrm{e} \AA^{-3}\right)$ & $4.28,-1.93$ \\
\hline
\end{tabular}

Refinement Details: The crystal under investigation was found to be non-merohedrally twinned. The orientation matrices for the two components were identified using the program Cell_Now, with the two components being related by a $180^{\circ}$ rotation around the reciprocal axis $(1-10)$. The two components were integrated using Saint and corrected for absorption using twinabs, resulting in the following statistics:

30967 data (10749 unique) involve domain 1 only, mean I/sigma 10.3 30918 data (10739 unique) involve domain 2 only, mean I/sigma 8.4 28426 data (11865 unique) involve 2 domains, mean I/sigma 13.2

The exact twin matrix identified by the integration program was found to be: 
$\begin{array}{lll}0.05247 & -0.94725 & -0.00443\end{array}$

$-1.05278-0.05246 \quad 0.00446$

$0.00035-0.00044-1.00001$

The structure was solved using direct methods with only the non-overlapping reflections of component 1 . The structure was refined using the hklf 5 routine with all reflections of component 1 (including the overlapping ones), resulting in a BASF value of 0.4242(5).

The $\mathrm{R}_{\text {int }}$ value given is for all reflections and is based on agreement between observed single and composite intensities and those calculated from refined unique intensities and twin fractions (TWINABS (Sheldrick, 2012)).

The disorder of the 2,6-diisopropylphenyl group was refined by refining the ring and one isopropyl group as two moieties. The two disordered moieties were restrained to have similar geometries. $\mathrm{U}^{\mathrm{ij}}$ components of ADPs for disordered atoms closer to each other than 2.0 Ångström were restrained to be similar. Then the ring was restrained to be planar. Subject to these conditions the occupancy ratios refined to $0.56(2)$ and $0.44(2)$.

The disorder in one of the DCM solvate molecules was refined as two moieties but were restrained to be similar to the non-disordered DCM solvate molecule. $\mathrm{U}^{\mathrm{ij}}$ components of ADPs for disordered atoms closer to each other than 2.0 Ångström were restrained to be similar. Subject to these conditions the occupancy ratios refined to $0.811(7)$ and $0.189(7)$.

The following two reflections were omitted:

$-102$

$-3421$

Computer programs: Apex3 v2016.9-0 (Bruker, 2016), SAINT V8.37A (Bruker, 2016), SHELXS97 (Sheldrick, 2008), SHELXL2017/8 (Sheldrick, 2014), SHELXLE Rev714 (Hübschle et al., 2011). 
Local Name: RR98_0m_sq_final

CCDC: 2038475

Table S3. Crystallographic details for 3-isq

\begin{tabular}{|c|c|}
\hline \multicolumn{2}{|l|}{ Crystal data } \\
\hline Chemical formula & $\mathrm{C}_{78} \mathrm{H}_{111} \mathrm{ClN}_{3} \mathrm{O}_{3} \mathrm{Th} \cdot[+$ solvent $]$ \\
\hline$M_{\mathrm{r}}$ & 1406.18 \\
\hline $\begin{array}{l}\text { Crystal system, space } \\
\text { group }\end{array}$ & Trigonal, $R 3: H$ \\
\hline Temperature $(\mathrm{K})$ & 150 \\
\hline$a, c(\AA)$ & $17.9787(8), 29.0450(15)$ \\
\hline$V\left(\AA^{3}\right)$ & $8130.5(8)$ \\
\hline$Z$ & 3 \\
\hline Radiation type & Mo $K \alpha$ \\
\hline$\mu\left(\mathrm{mm}^{-1}\right)$ & 1.43 \\
\hline Crystal size (mm) & $0.35 \times 0.22 \times 0.17$ \\
\hline \multicolumn{2}{|l|}{ Data collection } \\
\hline Diffractometer & Bruker AXS D8 Quest CMOS diffractometer \\
\hline Absorption correction & $\begin{array}{l}\text { Multi-scan - SADABS 2016/2: Krause, L., Herbst-Irmer, R., Sheldrick } \\
\text { G.M. \& Stalke D. (2015). J. Appl. Cryst. } 48 \text { 3-10. }\end{array}$ \\
\hline$T_{\min }, T_{\max }$ & $0.651,0.747$ \\
\hline $\begin{array}{l}\text { No. of measured, } \\
\text { independent and } \\
\text { observed }[I>2 \sigma(I)] \\
\text { reflections }\end{array}$ & $80168,13771,13647$ \\
\hline$R_{\text {int }}$ & 0.040 \\
\hline$(\sin \theta / \lambda)_{\max }\left(\AA^{-1}\right)$ & 0.770 \\
\hline \multicolumn{2}{|l|}{ Refinement } \\
\hline$R\left[F^{2}>2 \sigma\left(F^{2}\right)\right], w R\left(F^{2}\right), S$ & $0.020,0.036,0.98$ \\
\hline No. of reflections & 13771 \\
\hline No. of parameters & 300 \\
\hline No. of restraints & 46 \\
\hline H-atom treatment & H-atom parameters constrained \\
\hline$\Delta \rho_{\max }, \Delta \rho_{\min }\left(\mathrm{e} \AA^{-3}\right)$ & $0.31,-0.58$ \\
\hline Absolute structure & $\begin{array}{l}\text { Flack x determined using } 6588 \text { quotients [(I+)-(I-)]/[(I+)+(I-)] (Parsons, } \\
\text { Flack and Wagner, Acta Cryst. B69 (2013) 249-259). } \\
\end{array}$ \\
\hline $\begin{array}{l}\text { Absolute structure } \\
\text { parameter }\end{array}$ & $-0.0232(15)$ \\
\hline
\end{tabular}

Refinement Details: The two disordered moieties of the tert-butyl group were restrained to have similar geometries. $\mathrm{U}^{\mathrm{ij}}$ components of ADPs for disordered atoms closer to each other than 2.0 Ångström were restrained to be similar. Subject to these conditions the occupancy ratio refined to $0.601(4)$ to $0.399(4)$. 
The structure contains 1 independent solvent accessible voids of 3289 Ångström ${ }^{3}$ combined. No substantial electron density peaks were found in the solvent accessible voids (less than 1.613 electron per cubic Ångström) and the residual electron density peaks are not arranged in an interpretable pattern. The structure factors were instead augmented via reverse Fourier transform methods using the SQUEEZE routine (P. van der Sluis \& A.L. Spek (1990). Acta Cryst. A46, 194201) as implemented in the program Platon. The resultant FAB file containing the structure factor contribution from the electron content of the void space was used in together with the original hkl file in the further refinement. (The FAB file with details of the Squeeze results is appended to this cif file). The Squeeze procedure corrected for 703 electrons within the solvent accessible voids.

Computer programs: Apex3 v2016.9-0 (Bruker, 2016), SAINT V8.37A (Bruker, 2016), SHELXS97 (Sheldrick, 2008), SHELXL2017/8 (Sheldrick, 2014), SHELXLE Rev714 (Hübschle et al., 2011). 
Local Name: RR108_0m_final

CCDC: 2038478

Table S4. Crystallographic details for 4-ap

\begin{tabular}{|c|c|}
\hline \multicolumn{2}{|l|}{ Crystal data } \\
\hline Chemical formula & $\mathrm{C}_{82} \mathrm{H}_{119} \mathrm{~K}_{2} \mathrm{~N}_{3} \mathrm{O}_{4} \mathrm{Th} \cdot 2\left(\mathrm{C}_{7} \mathrm{H}_{8}\right)$ \\
\hline$M_{\mathrm{r}}$ & 1705.30 \\
\hline Crystal system, space group & Triclinic, $P \overline{1}$ \\
\hline Temperature $(\mathrm{K})$ & 150 \\
\hline$a, b, c(\AA)$ & $12.9517(6), 14.5959(7), 25.8003(13)$ \\
\hline$\alpha, \beta, \gamma\left({ }^{\circ}\right)$ & $83.535(2), 78.102(2), 70.835(2)$ \\
\hline$V\left(\AA^{3}\right)$ & $4502.7(4)$ \\
\hline$Z$ & 2 \\
\hline Radiation type & Mo $K \alpha$ \\
\hline$\mu\left(\mathrm{mm}^{-1}\right)$ & 1.80 \\
\hline Crystal size $(\mathrm{mm})$ & $0.37 \times 0.16 \times 0.05$ \\
\hline \multicolumn{2}{|l|}{ Data collection } \\
\hline Diffractometer & Bruker AXS D8 Quest CMOS diffractometer \\
\hline Absorption correction & $\begin{array}{l}\text { Multi-scan - SADABS 2016/2: Krause, L., Herbst-Irmer, R., } \\
\text { Sheldrick G.M. \& Stalke D. (2015). J. Appl. Cryst. } 48 \text { 3-10. }\end{array}$ \\
\hline$T_{\min }, T_{\max }$ & $0.597,0.746$ \\
\hline $\begin{array}{l}\text { No. of measured, independent and } \\
\text { observed }[I>2 \sigma(I)] \text { reflections }\end{array}$ & $176520,30118,26033$ \\
\hline$R_{\text {int }}$ & 0.049 \\
\hline$(\sin \theta / \lambda)_{\max }\left(\AA^{-1}\right)$ & 0.737 \\
\hline \multicolumn{2}{|l|}{ Refinement } \\
\hline$R\left[F^{2}>2 \sigma\left(F^{2}\right)\right], w R\left(F^{2}\right), S$ & $0.028,0.065,1.03$ \\
\hline No. of reflections & 30118 \\
\hline No. of parameters & 1131 \\
\hline No. of restraints & 564 \\
\hline H-atom treatment & H-atom parameters constrained \\
\hline$\Delta \rho_{\max }, \Delta \rho_{\min }\left(\mathrm{e} \AA^{-3}\right)$ & $3.36,-1.60$ \\
\hline
\end{tabular}

Refinement Details: The two disordered moieties of the THF were restrained to have similar geometries. $U^{\mathrm{ij}}$ components of ADPs for disordered atoms closer to each other than 2.0 Ångström were restrained to be similar. The ADPs of the oxygen atoms were constrained to be identical. Subject to these conditions the occupancy ratio refined to $0.519(11)$ to $0.481(11)$.

There are two solvent toluene molecules disordered around an inversion center. The methyl group of one of the two molecules is in conflict with its symmetry related counterpart across the inversion center, thus necessitating an exact 0.5 to 0.5 disorder ratio. The six-membered rings of the toluene molecules were constrained to resemble exact hexagons with $\mathrm{C}-\mathrm{C}$ distances of 1.39 Ångström (AFIX 66 constraint of Shelxl). The $\mathrm{C}-\mathrm{C}$ (methyl) bond distances were restrained to a target value of 1.53(2) Ångström. The C(methyl) to C(ortho) distances were restrained to be similar in length. 
Uij components of ADPs for disordered atoms closer to each other than 2.0 Ångström were restrained to be similar, and ADPs to be close to isotropic.

Associated with the solvate toluene disorder is disorder of a toluene bound to a potassium ion in close proximity to the solvate toluene molecules. It was also refined with a 0.5 to 0.5 disorder ratio. The two moieties were restrained to have similar geometries. Uij components of ADPs for disordered atoms closer to each other than 2.0 Ångström were restrained to be similar.

Computer programs: Apex3 v2016.9-0 (Bruker, 2016), SAINT V8.37A (Bruker, 2016), SHELXS97 (Sheldrick, 2008), SHELXL2017/8 (Sheldrick, 2014), SHELXLE Rev714 (Hübschle et al., 2011). 
Local Name: RR164_0m_sq_final

CCDC: 2038476

Table S5. Crystallographic details for 4-ap mono crypt

\begin{tabular}{|c|c|}
\hline \multicolumn{2}{|l|}{ Crystal data } \\
\hline Chemical formula & $\mathrm{C}_{78} \mathrm{H}_{111} \mathrm{KN}_{3} \mathrm{O}_{3} \mathrm{Th} \cdot \mathrm{C}_{18} \mathrm{H}_{36} \mathrm{KN}_{2} \mathrm{O}_{6} \cdot 3\left(\mathrm{C}_{4} \mathrm{H}_{10} \mathrm{O}\right) \cdot[+$ solvent $]$ \\
\hline$M_{\mathrm{r}}$ & 2047.78 \\
\hline Crystal system, space group & Hexagonal, $P 6_{3}$ \\
\hline Temperature (K) & 150 \\
\hline$a, c(\AA)$ & $16.5711(8), 24.1987(12)$ \\
\hline$V\left(\AA^{3}\right)$ & $5754.7(6)$ \\
\hline$Z$ & 2 \\
\hline Radiation type & Mo $K \alpha$ \\
\hline$\mu\left(\mathrm{mm}^{-1}\right)$ & 1.42 \\
\hline Crystal size $(\mathrm{mm})$ & $0.24 \times 0.15 \times 0.06$ \\
\hline \multicolumn{2}{|l|}{ Data collection } \\
\hline Diffractometer & Bruker AXS D8 Quest CMOS diffractometer \\
\hline Absorption correction & $\begin{array}{l}\text { Multi-scan - SADABS 2016/2: Krause, L., Herbst-Irmer, R., } \\
\text { Sheldrick G.M. \& Stalke D., J. Appl. Cryst. } 48 \text { (2015) 3-10 }\end{array}$ \\
\hline$T_{\min }, T_{\max }$ & $0.203,0.269$ \\
\hline $\begin{array}{l}\text { No. of measured, independent and } \\
\text { observed }[I>2 \sigma(I)] \text { reflections }\end{array}$ & $119648,9514,7265$ \\
\hline$R_{\text {int }}$ & 0.076 \\
\hline$(\sin \theta / \lambda)_{\max }\left(\AA^{-1}\right)$ & 0.667 \\
\hline \multicolumn{2}{|l|}{ Refinement } \\
\hline$R\left[F^{2}>2 \sigma\left(F^{2}\right)\right], w R\left(F^{2}\right), S$ & $0.026,0.070,1.06$ \\
\hline No. of reflections & 9514 \\
\hline No. of parameters & 442 \\
\hline No. of restraints & 118 \\
\hline H-atom treatment & $\mathrm{H}$-atom parameters constrained \\
\hline$\Delta \rho_{\max }, \Delta \rho_{\min }\left(\mathrm{e} \AA^{-3}\right)$ & $1.44,-1.03$ \\
\hline Absolute structure & Refined as an inversion twin. \\
\hline Absolute structure parameter & $-0.032(8)$ \\
\hline
\end{tabular}

Refinement Details: Refined as a 2-component inversion twin.

A diethyl ether molecule was refined as disordered over two orientations. The two disordered moieties were restrained to have similar geometries. $U^{\mathrm{ij}}$ components of ADPs for disordered atoms closer to each other than 2.0 Ångström were restrained to be similar. The two moieties were disordered around a rotation axis and was modeled as such. Subject to these conditions the occupancy ratio refined to $0.227(8)$ to $0.773(8)$. Additionally, the C-C and C-O bonds of the two disordered ether moieties were restrained to have a similar length. 
The structure contains additional solvent accessible voids of $435 \AA^{\text {Angström }}{ }^{3}$ combined. No substantial electron density peaks were found in the solvent accessible voids (less than 1.6 electrons per cubic Ångström) and the residual electron density peaks are not arranged in an interpretable pattern. The structure factors were instead augmented via reverse Fourier transform methods using the SQUEEZE routine (P. van der Sluis \& A.L. Spek (1990). Acta Cryst. A46, 194201) as implemented in the program Platon. The resultant FAB file containing the structure factor contribution from the electron content of the void space was used in together with the original hkl file in the further refinement. (The FAB file with details of the Squeeze results is appended to the cif file). The Squeeze procedure corrected for 140 electrons within the solvent accessible voids.

Computer programs: Apex3 v2016.9-0 (Bruker, 2016), SAINT V8.37A (Bruker, 2016), SHELXS97 (Sheldrick, 2008), SHELXL2017/8 (Sheldrick, 2014), SHELXLE Rev714 (Hübschle et al., 2011). 
Local Name: RR174_0m_final

CCDC: 2038477

Table S6. Crystallographic details for 4-ap crypt

\begin{tabular}{|c|c|}
\hline \multicolumn{2}{|l|}{ Crystal data } \\
\hline Chemical formula & $\mathrm{C}_{78} \mathrm{H}_{111} \mathrm{~N}_{3} \mathrm{O}_{3} \mathrm{Th} \cdot 2\left(\mathrm{C}_{18} \mathrm{H}_{36} \mathrm{KN}_{2} \mathrm{O}_{6}\right) \cdot 2\left(\mathrm{C}_{4} \mathrm{H}_{8} \mathrm{O}\right)$ \\
\hline$M_{\mathrm{r}}$ & 2346.11 \\
\hline Crystal system, space group & Trigonal, $\mathrm{R} \overline{3}$ \\
\hline Temperature $(\mathrm{K})$ & 150 \\
\hline$a, c(\AA)$ & $16.5168(7), 85.447(5)$ \\
\hline$V\left(\AA^{3}\right)$ & $20187(2)$ \\
\hline$Z$ & 6 \\
\hline Radiation type & Mo $K \alpha$ \\
\hline$\mu\left(\mathrm{mm}^{-1}\right)$ & 1.23 \\
\hline Crystal size (mm) & $0.51 \times 0.29 \times 0.26$ \\
\hline \multicolumn{2}{|l|}{ Data collection } \\
\hline Diffractometer & Bruker AXS D8 Quest CMOS diffractometer \\
\hline Absorption correction & $\begin{array}{l}\text { Multi-scan } \\
\text { SADABS 2016/2: Krause, L., Herbst-Irmer, R., Sheldrick G.M. } \\
\text { \& Stalke D. (2015). J. Appl. Cryst. } 48 \text { 3-10. }\end{array}$ \\
\hline$T_{\min }, T_{\max }$ & $0.618,0.747$ \\
\hline $\begin{array}{l}\text { No. of measured, independent and } \\
\text { observed }[I>2 \sigma(I)] \text { reflections }\end{array}$ & $74311,17100,14696$ \\
\hline$R_{\text {int }}$ & 0.046 \\
\hline$(\sin \theta / \lambda)_{\max }\left(\AA^{-1}\right)$ & 0.770 \\
\hline \multicolumn{2}{|l|}{ Refinement } \\
\hline$R\left[F^{2}>2 \sigma\left(F^{2}\right)\right], w R\left(F^{2}\right), S$ & $0.046,0.128,1.09$ \\
\hline No. of reflections & 17100 \\
\hline No. of parameters & 768 \\
\hline No. of restraints & 991 \\
\hline H-atom treatment & H-atom parameters constrained \\
\hline & $\begin{array}{l}w=1 /\left[\sigma^{2}\left(F_{\mathrm{o}}^{2}\right)+(0.0671 P)^{2}+34.6168 P\right] \\
\text { where } P=\left(F_{\mathrm{o}}^{2}+2 F_{\mathrm{c}}^{2}\right) / 3\end{array}$ \\
\hline$\Delta \rho_{\max }, \Delta \rho_{\min }\left(\mathrm{e} \AA^{-3}\right)$ & $2.04,-2.90$ \\
\hline
\end{tabular}

Refinement Details: A potassium cryptand moiety is located offset on a three-fold rotinversion axis and was refined as disordered around this axis one third occupied, with the other two third fragments created by the rotation axis. The void space when the cryptand is rotated away is occupied by a THF molecule, which was refined as two thirds occupied so that all space is either occupied by segments of three overlapping third cryptands, or by a segment of one cryptand (one third occuped) and a THF molecule (two third occupied).

Each one third of the cryptand, ranging from nitrogen to nitrogen, was restrained to have a similar geometry as the same segment in the other not disordered cryptand in this structure. The nitrogen 
atoms were set to be shared between the three third fragments to allow for easier structure refinement (use of a SAME command) and were thus set to be one ninth occupied. The ADPs and positions of each three of the nine nitrogens were then constrained to be the same. The copied nitrogens were deleted from the connectivity list so there would only be one nitrogen carbon bond.

The occupancy ratio of the disordered THF moiety was set to 0.6667 because it is disordered with the one third occupied potassium cryptand moiety, see above. The atoms were restrained to be close to isotropic with an effective standard deviation 0.03 . The $\mathrm{C}-\mathrm{O}$ bonds of the THF were restrained to a target value 1.45(2) Ångström while the $\mathrm{C}-\mathrm{C}$ bonds were restrained to a target value of 1.53(2) Ångström. All 1,3 C-C and C-O bond distances of the THF molecule (aka the bond angles) was also restrained to have the same length.

The potassium cryptand disorder induces 2:1 disorder of one of the iminoquinone ligands. The two moieties were restrained to have similar geometries. $\mathrm{U}^{\mathrm{ij}}$ components of ADPs for disordered atoms closer to each other than 2.0 Ångström were restrained to be similar. Additionally, the ADPs and positions of the two oxygen and nitrogen atoms at the end of the disorder were constrained to be each the same. The atoms of the minor disordered moiety except the methyl groups were also restrained to be coplanar.

Computer programs: Apex3 v2016.9-0 (Bruker, 2016), SAINT V8.37A (Bruker, 2016), SHELXS97 (Sheldrick, 2008), SHELXL2017/8 (Sheldrick, 2014), SHELXLE Rev714 (Hübschle et al., 2011). 
Local Name: RR78_0m_final

CCDC: 2038473

Table S7. Crystallographic details for 5-ap.

\begin{tabular}{|c|c|}
\hline \multicolumn{2}{|l|}{ Crystal data } \\
\hline Chemical formula & $\mathrm{C}_{88} \mathrm{H}_{104} \mathrm{~N}_{2} \mathrm{O}_{4} \mathrm{P} \mathrm{P}_{2} \mathrm{Th} \cdot 2\left(\mathrm{C}_{4} \mathrm{H}_{10} \mathrm{O}\right) \cdot[+$ solvent $]$ \\
\hline$M_{\mathrm{r}}$ & 1695.94 \\
\hline Crystal system, space group & Tetragonal, $P 4_{2} / n$ \\
\hline Temperature $(\mathrm{K})$ & 150 \\
\hline$a, c(\AA)$ & $20.5872(6), 24.3693(8)$ \\
\hline$V\left(\AA^{3}\right)$ & $10328.5(7)$ \\
\hline$Z$ & 4 \\
\hline Radiation type & $\mathrm{Cu} K \alpha$ \\
\hline$\mu\left(\mathrm{mm}^{-1}\right)$ & 5.29 \\
\hline Crystal size (mm) & $0.21 \times 0.10 \times 0.08$ \\
\hline \multicolumn{2}{|l|}{ Data collection } \\
\hline Diffractometer & Bruker AXS D8 Quest CMOS diffractometer \\
\hline Absorption correction & $\begin{array}{l}\text { Multi-scan - SADABS 2016/2: Krause, L., Herbst-Irmer, R., } \\
\text { Sheldrick G.M. \& Stalke D. (2015). J. Appl. Cryst. } 48 \text { 3-10. }\end{array}$ \\
\hline$T_{\min }, T_{\max }$ & $0.344,0.754$ \\
\hline $\begin{array}{l}\text { No. of measured, independent and } \\
\text { observed }[I>2 \sigma(I)] \text { reflections }\end{array}$ & $44582,10311,7253$ \\
\hline$R_{\text {int }}$ & 0.092 \\
\hline$(\sin \theta / \lambda)_{\max }\left(\AA^{-1}\right)$ & 0.625 \\
\hline \multicolumn{2}{|l|}{ Refinement } \\
\hline$R\left[F^{2}>2 \sigma\left(F^{2}\right)\right], w R\left(F^{2}\right), S$ & $0.061,0.173,1.03$ \\
\hline No. of reflections & 10311 \\
\hline No. of parameters & 611 \\
\hline No. of restraints & 276 \\
\hline \multirow{2}{*}{$\mathrm{H}$-atom treatment } & $\mathrm{H}$-atom parameters constrained \\
\hline & $\begin{array}{l}w=1 /\left[\sigma^{2}\left(F_{\mathrm{o}}^{2}\right)+(0.0852 P)^{2}+26.4434 P\right] \\
\text { where } P=\left(F_{\mathrm{o}}^{2}+2 F_{\mathrm{c}}^{2}\right) / 3\end{array}$ \\
\hline$\Delta \rho_{\max }, \Delta \rho_{\min }\left(\mathrm{e} \AA^{-3}\right)$ & $1.67,-2.07$ \\
\hline
\end{tabular}

Refinement Details: Two disordered isopropyl moieties were restrained to have similar geometries. $\mathrm{U}^{\mathrm{ij}}$ components of ADPs for disordered atoms closer to each other than 2.0 Ångström were restrained to be similar. Subject to these conditions the occupancy ratio refined to $0.58(6)$ to $0.42(6)$.

Two disordered moieties of the phenyl group in the triphenylphosphine oxide were restrained to have similar geometries. $\mathrm{U}^{\mathrm{ij}}$ components of ADPs for disordered atoms closer to each other than 2.0 Ångström were restrained to be similar. Subject to these conditions the occupancy ratio refined to $0.69(4)$ to $0.31(4)$. 
Two disordered moieties of the ether molecules were restrained to have similar geometries. $\mathrm{U}^{\mathrm{ij}}$ components of ADPs for disordered atoms closer to each other than 2.0 Ångström were restrained to be similar. Subject to these conditions the occupancy ratio refined to 0.641(8) to 0.359(8). The lesser occupied moiety is in conflict with its symmetry equivalent counterpart across an inversion center. The higher occupancy moiety overlaps with diffuse solvent not resolved in difference density maps extending into a neighboring void space.

The structure contains two of these solvent accessible voids of 1966 Angström ${ }^{3}$ combined. No substantial electron density peaks were found in the solvent accessible voids (less than 2.031 electrons per cubic Ångström) and the residual electron density peaks are not arranged in an interpretable pattern. The structure factors were instead augmented via reverse Fourier transform methods using the SQUEEZE routine (P. van der Sluis \& A.L. Spek (1990). Acta Cryst. A46, 194201) as implemented in the program Platon. The resultant FAB file containing the structure factor contribution from the electron content of the void space was used together with the original hkl file in the further refinement. (The FAB file with details of the Squeeze results is appended to the cif file). The Squeeze procedure corrected for 290 electrons within the solvent accessible voids.

Computer programs: Apex3 v2016.9-0 (Bruker, 2016), SAINT V8.37A (Bruker, 2016), SHELXS97 (Sheldrick, 2008), SHELXL2017/8 (Sheldrick, 2014), SHELXLE Rev714 (Hübschle et al., 2011).

\section{$\underline{\text { References }}$}

[1] Bruker (2016). Apex3 v2017.3-0, Saint V8.38A, Bruker AXS Inc.: Madison (WI), USA, 2013/2014.

[2] a) SHELXTL suite of programs, Version 6.14, 2000-2003, Bruker Advanced X-ray Solutions, Bruker AXS Inc., Madison, Wisconsin: USA b) Sheldrick GM. A short history of SHELX. Acta Crystallogr A. 2008, 64(1), 112-122.

[3] a) Sheldrick GM. University of Göttingen, Germany, 2018. b) Sheldrick GM. Crystal structure refinement with SHELXL. Acta Crystallogr Sect C Struct Chem. 2015, 71(1), 3-8.

[4] Hübschle CB, Sheldrick GM, Dittrich B. ShelXle: a Qt graphical user interface for SHELXL. J. Appl. Crystallogr. 2011, 44(6), 1281-1284. 